\title{
Microcracking in calcite and dolomite marble: microstructural influences and effects on properties
}

\author{
Victoria Shushakova $\cdot$ Edwin R. Fuller Jr. • \\ Siegfried Siegesmund
}

Received: 10 July 2012/Accepted: 12 September 2012/Published online: 25 September 2012

(C) The Author(s) 2012. This article is published with open access at Springerlink.com

\begin{abstract}
Microstructure-based finite-element analysis with a microcracking algorithm was used to simulate an actual degradation phenomenon of marble structures, i.e., microcracking. Both microcrack initiation and crack propagation were characterized, as were their dependence on lattice preferred orientation (LPO), grain shape preferred orientation (SPO), grain size, marble composition (calcite and dolomite) and grain-boundary fracture toughness. Two LPOs were analyzed: a random orientation distribution function and an orientation distribution function with strong directional crystalline texture generated from a MarchDollase distribution. Three SPOs were considered: equiaxed grains; elongated grains and a mixture of equiaxed and elongated grains. Three different grain sizes were considered: fine grains of order $200 \mu \mathrm{m}$ (only calcitic marble); medium size grains of order $1 \mathrm{~mm}$ (calcitic and dolomitic marbles); and large grains of order $2 \mathrm{~mm}$ (only dolomitic marble). The fracture surface energy for the grain boundaries, $\gamma_{\mathrm{ig}}$, was chosen to be 20 and $40 \%$ of the fracture surface energy of a grain, $\gamma_{x t a l}$, so that both intergranular and transgranular fracture were possible. Studies were performed on these idealized marble microstructures to elucidate the range of microcracking responses. Simulations were performed for both heating and cooling by $50{ }^{\circ} \mathrm{C}$ in steps of $1{ }^{\circ} \mathrm{C}$. Microcracking results were correlated with the thermoelastic responses, which are indicators related to degradation. The results indicate that certain combinations of LPO, SPO, grain size, grain-boundary fracture toughness and marble composition have a significant influence on the thermal-elastic response of marble. Microstructure with the
\end{abstract}

V. Shushakova $(\bowtie) \cdot$ E. R. Fuller Jr. · S. Siegesmund Geowissenschaftliches Zentrum der Universität Göttingen, Goldschmidtstrasse 3, 37077 Göttingen, Germany

e-mail: victoria.shushakova@gmail.com smallest grain size and the highest degree of SPO and LPO had less of a tendency to microcrack. Additionally, with increasing SPO and LPO microcracking becomes more spatially anisotropic. A significant observation for all microstructures was an asymmetry in microcracking upon heating and cooling: more microcracking was observed upon cooling than upon heating. Given an identical microstructure and crystallographic texture, calcite showed larger thermal stresses than dolomite, had an earlier onset of microcracking upon heating and cooling, and a greater microcracked area at a given temperature differential. Thermal expansion coefficients with and without microcracking were also determined.

Keywords Marble $\cdot$ Microcracking $\cdot$ Finite-element modeling - Lattice preferred orientation - Shape preferred orientation - Strain energy density - Maximum principal stress - Thermal expansion coefficient - Thermal expansion anisotropy

\section{Introduction}

Marble has been used as decorative and constructive material since ancient times. However, marbles can be extremely sensitive to weathering and to degradation, and hence can have limited durability. The Taj Mahal, the famous masterpiece of architectural art (see Fig. 1), is a white marble mausoleum situated in Agra, India. Due to acid rain generated from an oil refinery and foundries, the marble façades on the Taj Mahal have been losing their luster, brightness, and white color into a sickly shade. Siegesmund et al. $(2000,2007)$ pointed out that physical weathering is thought to be the initial stage of marble degradation. 


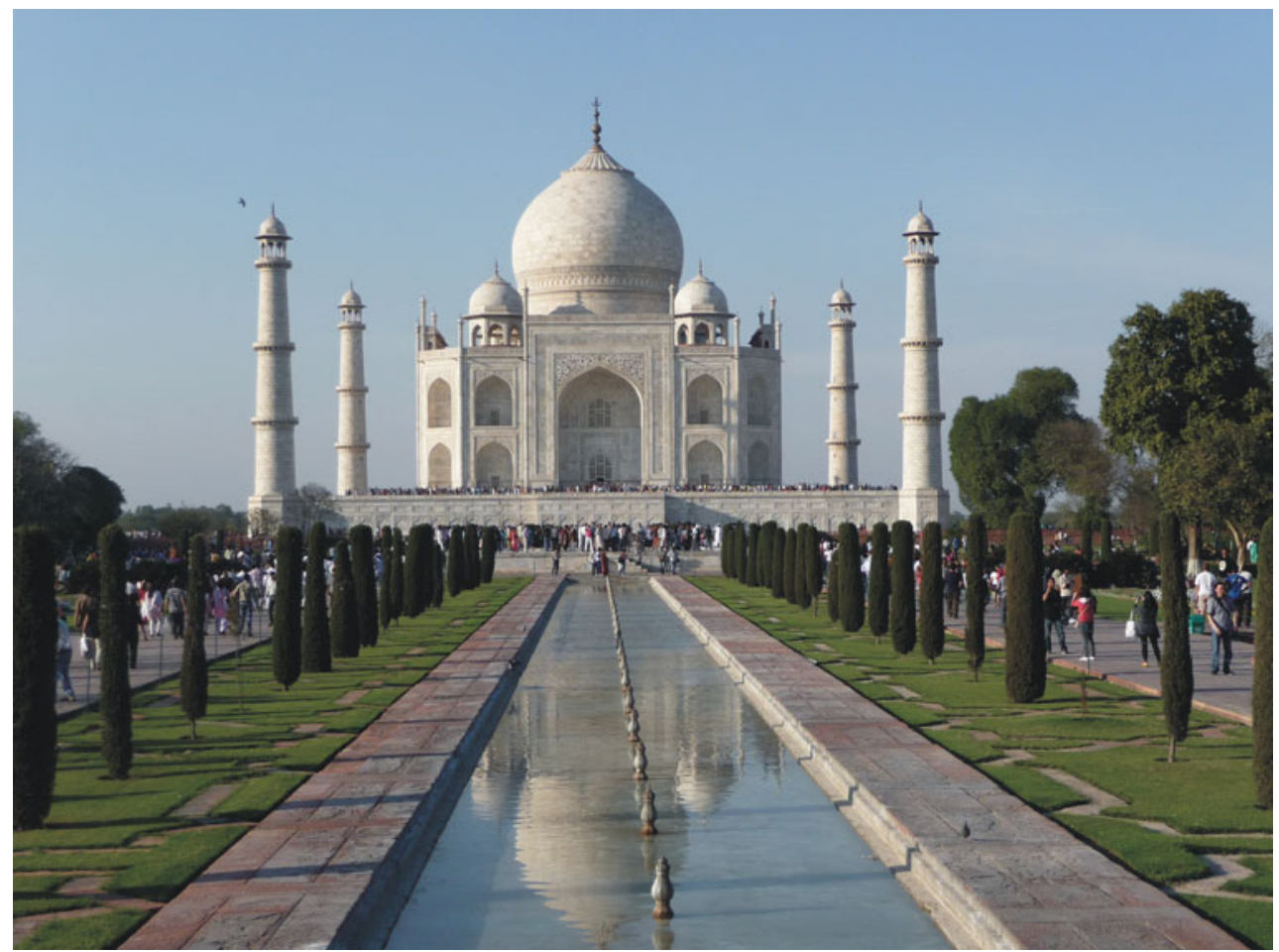

Fig. 1 Representative view of the façade of the Taj Mahal (Agra, India)
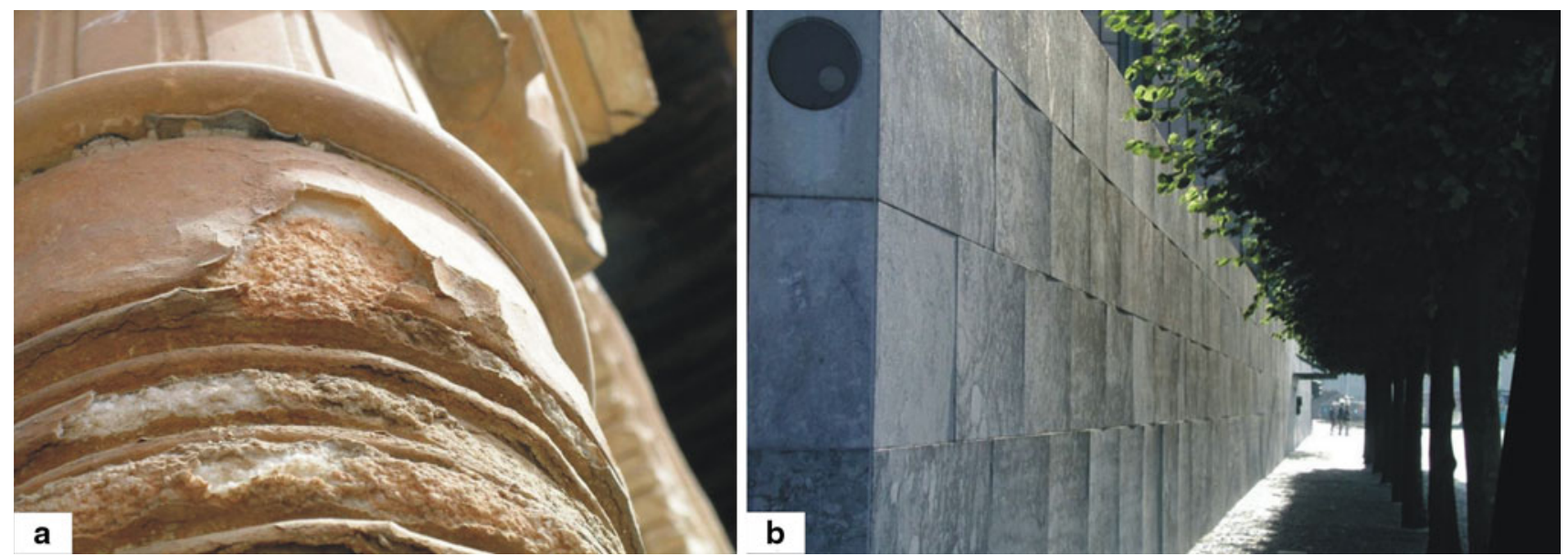

Fig. 2 Two examples of marble deterioration: a the weathered column of Alhambra Granada, Spain; and $\mathbf{b}$ bowing of marble façade panels in Copenhagen

Many historical marble sculptures and monuments show clear evidence of deterioration, which is visible as a loss of relief structure (Fig. 2a) or façade bowing (Fig. 2b). The reason for the degradation is mainly due to climate. Many studies have shown that increases and decreases of temperature can induce these degradation phenomena in marbles, e.g., Kessler (1919), Battaglia et al. (1993), Winkler (1994), Siegesmund et al. (2000), Zeisig et al. (2002).

Calcite and dolomite, the rock-forming minerals in marble, have a large anisotropy in their coefficients of thermal expansion along the different crystallographic directions. Consequently, in a polycrystalline structure the stochastic misfit strains produced by this thermal expansion anisotropy can produce large internal stresses, which occur mainly at triple junctions and along the grain boundaries (Siegesmund et al. 2000). Independently, or in combination with environment (e.g., moisture-assisted fracture), these stresses can result in degradation phenomena, such as microcracking and granular disintegration (Koch and Siegesmund 2004; Siegesmund et al. 2008). Hot-stage 
environmental scanning electron microscopy (ESEM) can be used to provide direct evidence of such degradation phenomena during thermal cycling. In Fig. 3 one can directly observe the formation and propagation of microcracks near a triple junction in marble during the first heating and then cooling cycle. Such in situ experiments provide great in-depth knowledge of degradation processes, e.g., the loss of cohesion and concomitant microcrack formation along grain boundaries, and confirms that the initial decay process in marbles results from temperature changes and the misfit strains that result from the anisotropy in thermal expansion of the marble crystals. Such thermal expansion anisotropy degrades calcitic marbles more than dolomitic marbles, and the degradation is more severe if the marbles have straight grain boundaries, e.g., Weiss et al. (2002), Siegesmund et al. (2000), Luque et al. (2011).

Many fabric parameters influence this thermal degradation, notably, lattice preferred orientation (LPO), shape preferred orientation (SPO), grain size, grain-boundary toughness, grain-to-grain misorientation (Siegesmund et al. 2000; Weiss et al. 2002, 2003, 2004; Saylor et al. 2007; Siegesmund et al. 2008; Zeisig et al. 2002; Shushakova et al.
2011) and marble composition (Royer-Carfagni 1999; Siegesmund et al. 2000), as well as the single-crystal properties of the rock-forming minerals. Additionally, as has already been mentioned, the type of grain boundaries is an important factor that determines the behavior of marbles during thermal tests. Simple grain boundaries indicate a lower binding energy between them and interlobate or seriate grain boundaries reflect higher binding energy between grains (see Siegesmund et al. 2000; Grelk et al. 2004).

The goal of the present study is to establish the influence of fabric parameters on the propensity and degree of microcracking in marble structures, and to relate the degradation to microstructural indicators, such as stored energy strain density and maximum principal stress. Twodimensional finite-element simulations are used to elucidate microcracking initiation and propagation in calcitic and dolomitic marbles. The influence of fabric parameters include: extremes of crystallographic texture, a random orientation distribution function (ODF) and crystallographic texture 20 times a random ODF; three morphological types of microstructures; different grain sizes; different grain-boundary toughness; and different marble composition.
Fig. 3 Thermally induced microcrack formation observed in a hot-stage environmental scanning electron microscopy (ESEM) on a marble sample upon heating and then cooling. Sketches in the right column illustrate schematically: a the initial rock fabric; $\mathbf{b}$ the red arrows shows the crack opening onset during heating due to dilatation; and $\mathbf{c}$ the green arrows illustrate the crack closure on cooling and the resulting formation of new cracks, when closure is hindered
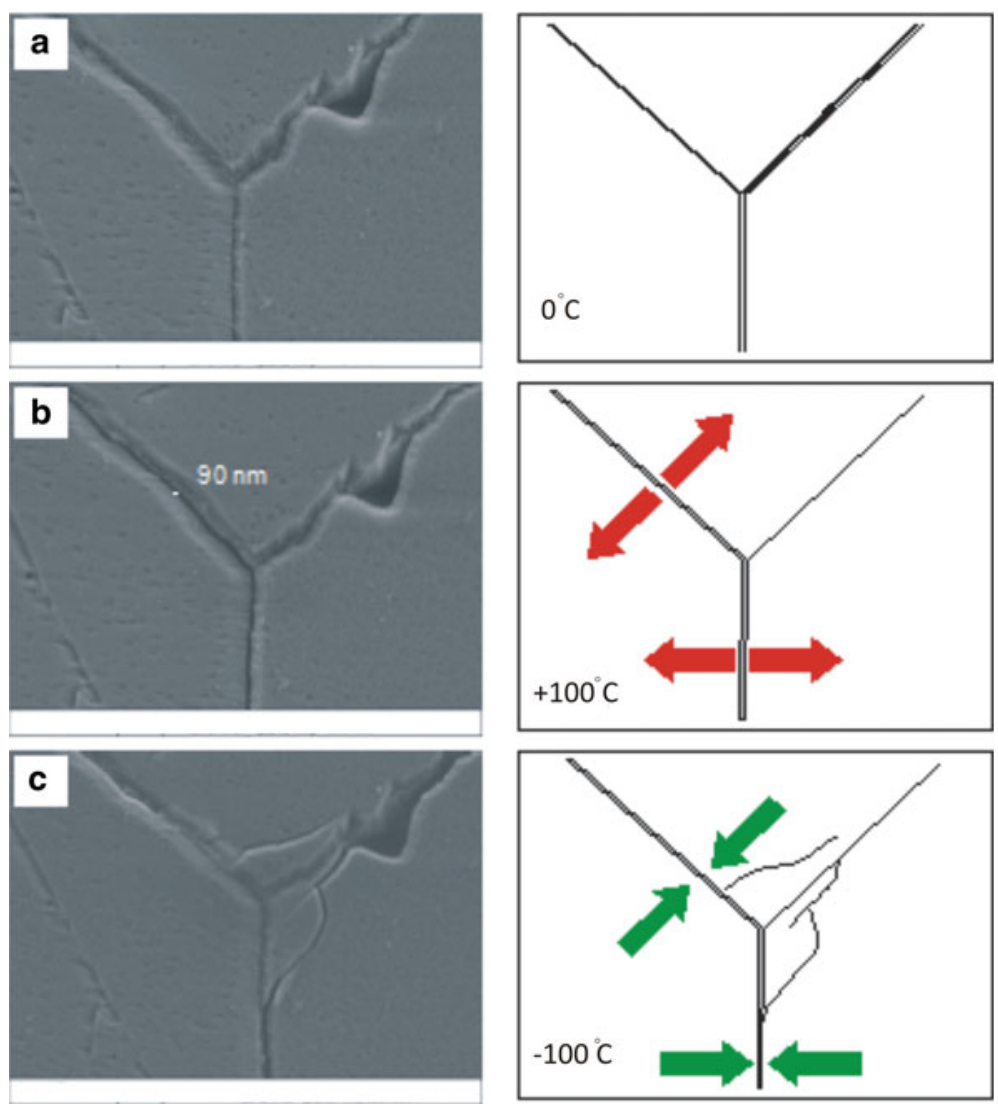


\section{Methods}

\section{Microstructure}

Two-dimensional hypothetical rock microstructures were used as input micrographs for the finite-element simulations. They were generated by using a nucleation and growth algorithm, which is described elsewhere (Ito and Fuller 1993; Miodownik et al. 1999; Saylor et al. 2004, 2007; Shushakova et al. 2011). Three types of SPO were examined: equiaxed grains; elongated grains; and a mixture of equiaxed and elongated grains (see Fig. 4). The microstructural images used for this study have a resolution of $1,000 \times 1,000$ pixels. The number of grains in the equiaxed, mixed, and elongated microstructures are 382 grains, 347 grains, and 312, respectively.

When fracture is included as a phenomenon in finiteelement simulations, the material now has a length scale (namely, the fracture surface energy divided by an elastic modulus), by which to measure grain size. Heretofore (e.g., Shushakova et al. 2011), outputs from microstructurebased simulations (e.g., elastic strain energy density and maximum principal stress) were independent of grain size; the only units being those of strain energy density $\left(\mathrm{kJ} \mathrm{m}^{-3}=10^{-6} \mathrm{GPa}\right)$ or stress $(\mathrm{GPa})$. Now, grain size, or equivalently, the size of the microstructural image, is important as it influences the parameter that is input into the simulation for the fracture surface energy. Accordingly, we introduce grain size as an important fabric, or microstructural parameter. We consider here three grain sizes: $200 \mu \mathrm{m} ; 1 \mathrm{~mm}$; and $2 \mathrm{~mm}$. However, due to the complexity of three SPOs in the present simulations (e.g., two different grain distributions in the mixed microstructure and non-equiaxed grains in the elongated microstructure), a better dimensional metric is the size of the microstructural image. Thus, the grain diameters for equiaxed grains and the grain widths for elongated grains were measured for a representative number of grains in each SPO microstructure. Using an average of these values to compute a nominal average grain size, the size of the microstructure was adjusted to give the three nominal average grain sizes. For a nominal average grain size of $1 \mathrm{~mm}$, the size of the micrograph for the equiaxed and the mixed microstructure is $16.13 \mathrm{~mm} \times 16.13 \mathrm{~mm}$, and the size for the elongated microstructure is $13.89 \mathrm{~mm} \times 13.89 \mathrm{~mm}$. Similarly, when the nominal average grain size is $200 \mu \mathrm{m}$ and $2 \mathrm{~mm}$, the sizes of the micrographs (edge lengths), respectively, are 3.125 and $31.25 \mathrm{~mm}$ for the equiaxed and mixed microstructure, and 2.778 and $27.78 \mathrm{~mm}$ for the elongated microstructure.

The laboratory reference frame is specified in Fig. 4 by the Cartesian vectors $e_{i}, i=1,2,3$. The $e_{1}$ - and $e_{2}$-directions are in the plane of the microstructure, and generally point perpendicular and parallel to the SPO, respectively, if shape orientation is present. The $e_{3}$-direction is out of the plane of the microstructure and points perpendicular to the SPO.

\section{Crystalline texture}

To assign orientations to each grain, orientation distributions were generated via the March-Dollase distribution (Dollase 1986; Blendell et al. 2004). The applied algorithm here is described in detail elsewhere (Saylor et al. 2007; Shushakova et al. 2011). Given a texture direction, the crystallographic c-axes are distributed within a cone of half angle $\theta$ about the texture direction. The polar angle of the orientation, $\theta$, with respect to the texture direction is given by

$\theta=\arccos \sqrt{\frac{M(1-P)^{2}}{1+(1-P)^{2}(M-1)}}$

where $M$ is a "texture" parameter that characterizes the degree of texture and gives the value of the maximum in
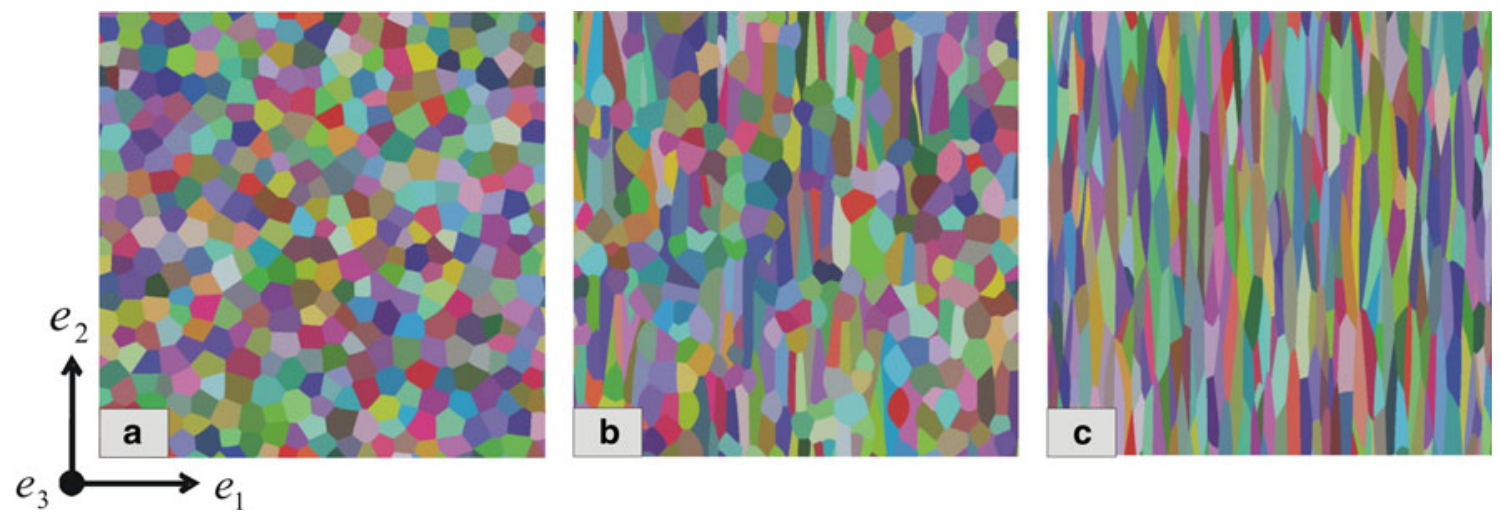

Fig. 4 Microstructures used for the finite-element modeling: a an equiaxed microstructure of 382 grains; $\mathbf{b}$ a mixed microstructure of 347 grains; and $\mathbf{c}$ an elongated microstructure of 312 grains. The coordinate system, $e_{i}$, is indicated 
the distribution in units of multiples of random distribution (MRD). $P$ is a random number selected between 0 and 1 .

After determining the polar angle, the two azimuthal angles of the orientation, $\varphi$ and $\omega$, are selected randomly in the range of $0-2 \pi$. Two different types of LPO were generated using $M$ values of 1 and 20 . With increasing value of $M$, the orientations become more textured, i.e., if $M=1$ the distribution is random, when $M=20$ we have a strong crystallographic texture.

Typical LPOs for marbles, as described in Leiss and Ullemeyer (1999), are textured with the c-axes perpendicular to the SPO. Accordingly, while there are many ways to align LPO with respect to SPO (e.g., three mutually orthogonal idealized configurations were considered by Shushakova et al. 2011), in the current simulations we have aligned the c-axes perpendicular to the shape fabric and out of plane, i.e., parallel to the $e_{3}$ direction. A representative pole figure for such texture is shown in Fig. 5 along with a pole figure for a random ODF. The pole figures show the individual poles of the crystallographic c-axis for each grain in the microstructure. The contour lines are selected MRD contours from the March-Dollase distribution, from which the orientations were chosen.

\section{Finite-element simulations}

For the finite-element simulations the microstructure-based object-oriented finite-element program (OOF), developed at the National Institute of Standards and Technology (Langer et al. 2001), was used. The OOF software is in the public domain. Executables, source code, and manuals are available at: http://www.nist.gov/mml/ctcms/oof/. The OOF1 software was used here.

An adaptive meshing algorithm was used to create a finite-element mesh with a grain-boundary phase that has the same thermoelastic properties and orientations as the host grains, but with a different fracture toughness, i.e., the grain-boundary toughness, $\gamma_{\text {ig }}$. The meshing procedure is described elsewhere (Langer et al. 2001; Weiss et al. 2002; Chawla et al. 2003; Saylor et al. 2007; Wanner et al. 2010). The final mesh consisted of 140,358 triangular elements for the equiaxed microstructure; 207,208 triangular elements for the mixed microstructure; and 163,668 elements for the elongated microstructure.

After creating the mesh, thermoelastic properties were assigned to the grains and to the grain boundaries according to which marble composition (calcite or dolomite) was being considered. The single-crystal elastic constants for both minerals, $C_{i j}$, (Bass 1995) and the crystalline coefficients of thermal expansion for calcite (Kleber 1959) and dolomite (Reeder and Markgraf 1986) were used (see Table 1).

Thirty unique configurations specified by SPO, LPO, grain size, grain-boundary toughness and marble composition were used in the simulations. Three different sets of orientations were generated for the calcite microstructures with equiaxed, mixed and elongated grains, random and 20 times random texture, a nominal grain size of $1 \mathrm{~mm}$, and a grain-boundary toughness of $40 \%$ of that for the grains. For other microstructural configurations only one replication of the ODF was used in the simulations. Thus, with replications, 42 configurations were used as the basis for the finite-element simulations.

Strain energy density and maximum principal stress were calculated for all microstructure configurations on heating and cooling by $50{ }^{\circ} \mathrm{C}$. Simulations were done with and without allowing microcracking to occur.

The fracture surface energy of single crystals is typically of order 0.3-1.1 $\mathrm{Jm}^{-2}$ (Becher and Freiman 1978; White et al. 1988). Accordingly, in the present simulations the crystalline or grain fracture toughness, $\gamma_{\mathrm{xtal}}$, for both calcite and dolomite was assumed to be $0.5 \mathrm{Jm}^{-2}$, and isotropic. Little is known about experimental values for the grainboundary toughness. Accordingly, to examine the influence of the intergranular fracture resistance, the grain-boundary toughness was assumed to be 40 and $20 \%$ of $\gamma_{x t a l}$, thus the
Fig. 5 Representative pole figures showing individual poles of the crystallographic $c$-axis for each grain in the microstructure: a orientations chosen from a random ODF; b orientations chosen from a March-Dollase ODF with fiber texture that is 20 times random along the NorthSouth pole. The contour lines correspond to MRDs from the March-Dollase distribution function of 16 (blue), 4 (green), 1 (orange) and $1 / 2$ (red). $c$-axis align parallel to the $e_{3}$ direction
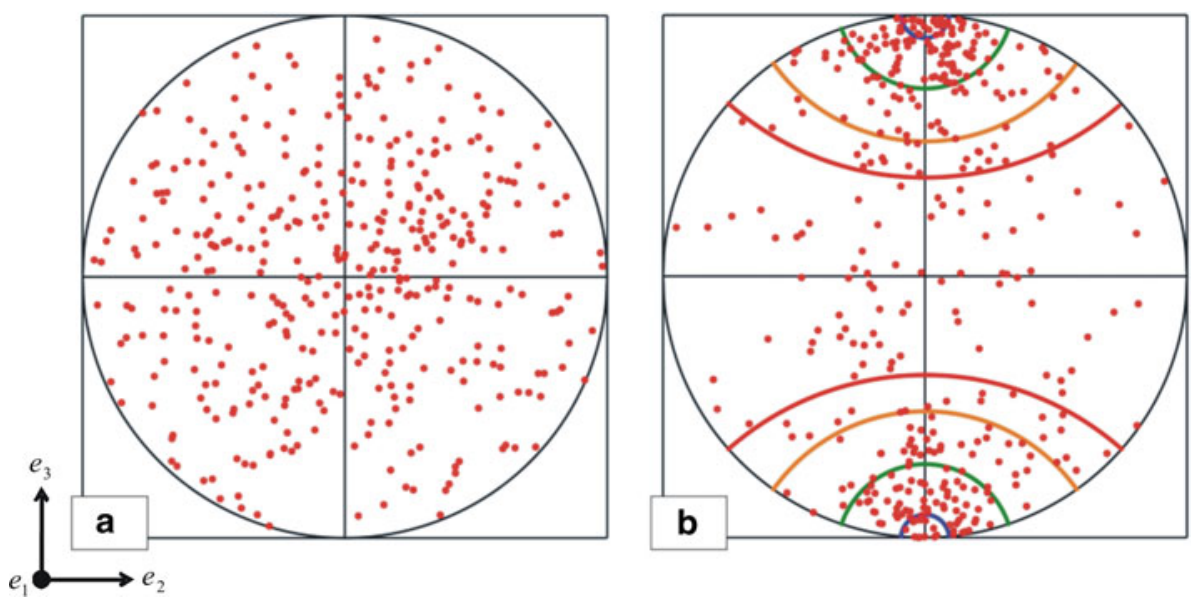
Table 1 The single-crystal elastic constants, $C_{i j}$, in GPa (Bass 1995) and the crystalline coefficients of thermal expansion, $\alpha_{i j}$, in $10^{-6}{ }^{\circ} \mathrm{C}^{-1}$ for calcite (Kleber 1959) and dolomite (Reeder and Markgraf 1986)

\begin{tabular}{|c|c|c|c|c|c|c|c|c|c|}
\hline Material & $C_{11}$ & $C_{12}$ & $C_{13}$ & $C_{14}$ & $C_{15}$ & $C_{33}$ & $C_{44}$ & $\alpha_{11}$ & $\alpha_{33}$ \\
\hline Calcite & 144.0 & 53.9 & 51.1 & -20.5 & 0 & 84.0 & 33.5 & -6.0 & 26.0 \\
\hline Dolomite & 205 & 70 & 57.4 & -19.5 & 13.7 & 113.0 & 39.8 & 6.0 & 26.0 \\
\hline
\end{tabular}

fracture resistance energy of the grain boundaries was $\gamma_{\mathrm{ig}}=0.2 \mathrm{Jm}^{-2}$ and $\gamma_{\mathrm{ig}}=0.1 \mathrm{Jm}^{-2}$, respectively. For simulations of microcrack initiation and crack propagation a Griffith-type fracture criterion was used. This criterion is based on the energy balance between mechanical and surface energy (Griffith 1921). How it is implemented in OOF is described in detail in Zimmermann et al. (2001) and Galal Yousef et al. (2005). Since the elastic constants input into OOF have units of GPa, the fracture surface energy has units of GPa times the size of the microstructure. Thus, by varying the input value of the fracture surface energy, one can vary the size of the microstructure, and hence, the nominal average grain size, as discussed above.

Fracturing in OOF is accomplished by reducing the directional elastic moduli (both the tensile and shear moduli) across the fracture plane by a multiplicative factors (Carter et al. 1998; Zimmermann et al. 2001; Galal Yousef et al. 2005). Multiplicative factors were chosen to be $1 \times 10^{-6}$ and $2 \times 10^{-6}$ in this study.

The finite-element simulations used two-dimensional elasticity with a plane-stress assumption, thereby simulating a free surface.

\section{Results and discussion}

\section{Effect of SPO and LPO}

The influence of SPO and LPO are illustrated for a calcitic marble with a nominal grain size of $1 \mathrm{~mm}$ and a grainboundary toughness of $40 \%$ of the single crystal toughness. Nonetheless, the results are general for all compositions and grain sizes. The results for this configuration are averaged over three replications of orientations (i.e., the ODFs) for the LPO distribution. For the equiaxed microstructure with a random $\operatorname{ODF}(M=1)$ the onset of microcracking on heating occurs at an average temperature change of $\Delta T=$ $15 \pm 2{ }^{\circ} \mathrm{C}$. For the mixed grain microstructure microcracking commences at $\Delta T=16 \pm 1{ }^{\circ} \mathrm{C}$, while for the elongated microstructure microcracking commences at $\Delta T=20 \pm 2{ }^{\circ} \mathrm{C}$. The elastic strain energy density and the maximum principal stress were monitored during heating and cooling for temperature step changes of $1{ }^{\circ} \mathrm{C}$ for both cracked and uncracked samples. The uncracked simulations are those for which the microcracking algorithm was not activated. The thermoelastic response values are plotted for the temperature interval from 10 to $50{ }^{\circ} \mathrm{C}$ during heating and from -10 to $-50{ }^{\circ} \mathrm{C}$ during cooling (see Fig. 6). The strain energy density and the maximum principal stress for the cracked state show a strong dependence on SPO for random crystallographic texture.

Microcracking in simulations with a highly textured LPO $(M=20)$ commences at a larger temperature increment from the unstressed state compared to the simulations with no texture, i.e., a random ODFs $(M=1)$. The equiaxed microstructure begins to microcrack at average of $\Delta T=18 \pm 1{ }^{\circ} \mathrm{C}$, while the microstructure with mixedshape fabric starts to crack at $\Delta T=18 \pm 4{ }^{\circ} \mathrm{C}$, and the elongated microstructure commences to crack at an even higher temperature differential of $\Delta T=23 \pm 4{ }^{\circ} \mathrm{C}$. The strain energy density and maximum principal stress for the fabric parameters are plotted in Fig. 7. A significant influence of SPO on the response of the cracked microstructures is observed upon heating; upon cooling the responses are similar.

The decrement in elastic strain energy density on microcracking (i.e., the difference between the strain energy density of the uncracked state and the cracked state) is the largest in the equiaxed microstructure with random texture (see Fig. 8). Since elastic strain energy is converted to fracture surface energy on microcracking, this result would suggest more microcracking in the equiaxed microstructure with random texture. To verify this conjecture, the averaged percentage of microcracked elements from three replications of the ODF are shown in Fig. 9 for a temperature change of $50{ }^{\circ} \mathrm{C}$ in both heating and cooling. The greatest extent of microcracking is observed in the equiaxed microstructure with random texture upon cooling (i.e., $9.1 \pm 0.3 \%$ of the total area at $\Delta T=-50{ }^{\circ} \mathrm{C}$ ). This is closely followed by the same microstructure upon heating (i.e., $7.8 \pm 0.2 \%$ at $\Delta T=+50{ }^{\circ} \mathrm{C}$ ). In the mixed graintype microstructure only $7.2 \pm 0.5 \%$ of whole area is microcracked upon cooling and $5.9 \pm 0.3 \%$ upon heating. Even fewer microcracks are observed in the elongated microstructure: $6.8 \pm 1.3 \%$ and $4.0 \pm 0.6 \%$ upon cooling and heating, respectively. In all microstructures more microcracking is observed upon cooling, than upon heating. The asymmetry is shown in Fig. 10 for an elongatedgrain microstructure with random texture. An apparent reason for this asymmetry is not obvious. 


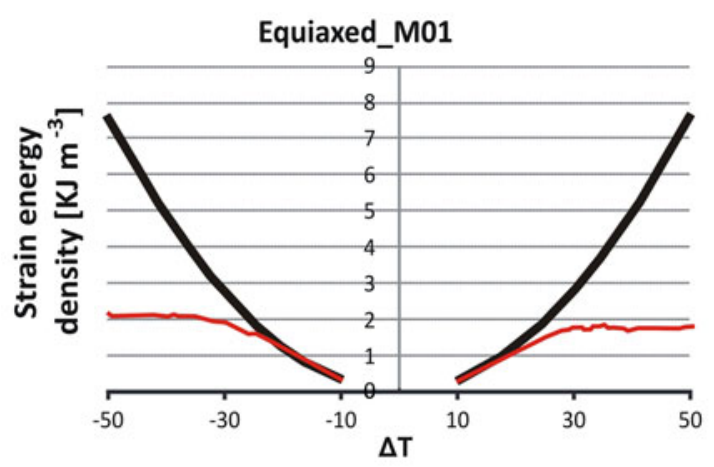

Mixed_M01

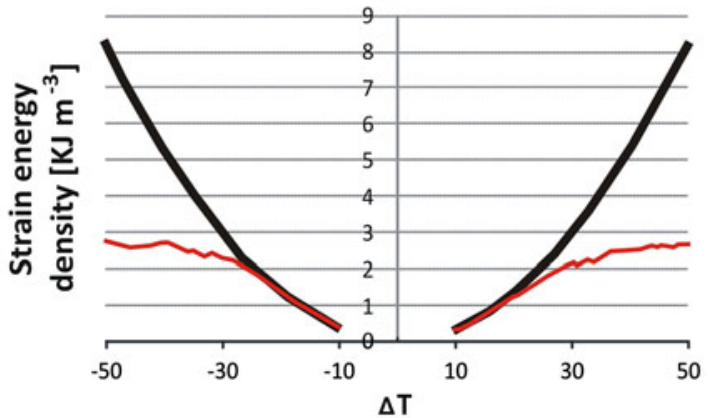

Elongated_M01
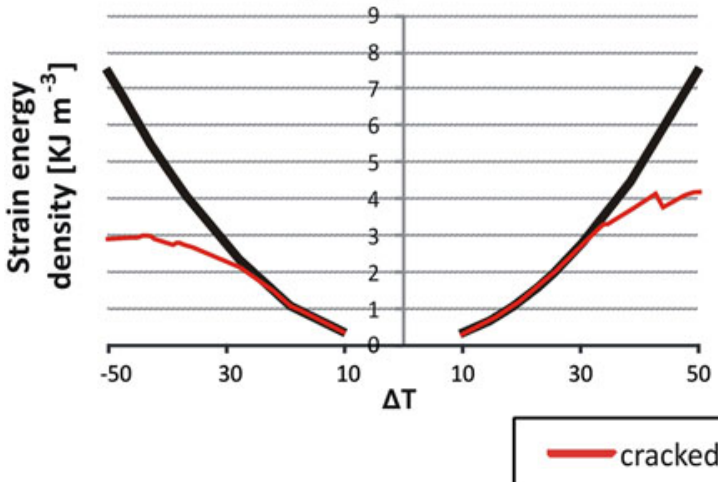

Fig. 6 Representative responses (a single replication of a random ODF) of the elastic strain energy density and the maximum principal stress for microcracked (red) and unmicrocracked (black) idealized marble microstructures versus the temperature change from the

When the crystallographic texture is 20 times random, the least amount of microcracking is observed in the elongated grain-type microstructure upon heating. Only $0.3 \pm 0.1 \%$ of the total area microcracks for a temperature change of $\Delta T=+50{ }^{\circ} \mathrm{C}$. In contrast, cooling the same microstructure results in $2.8 \pm 0.4 \%$ of the total area microcracking for a temperature change of $\Delta T=-50{ }^{\circ} \mathrm{C}$. In the mixed grain-type microstructure the amount of microcracking is $2.2 \pm 0.4 \%$ and $3.4 \pm 0.3 \%$ of the total area upon heating and cooling, respectively. For the highly textured material the most amount of microcracking is observed in the equiaxed microstructure with $3.8 \pm 0.1 \%$
Equiaxed_M01

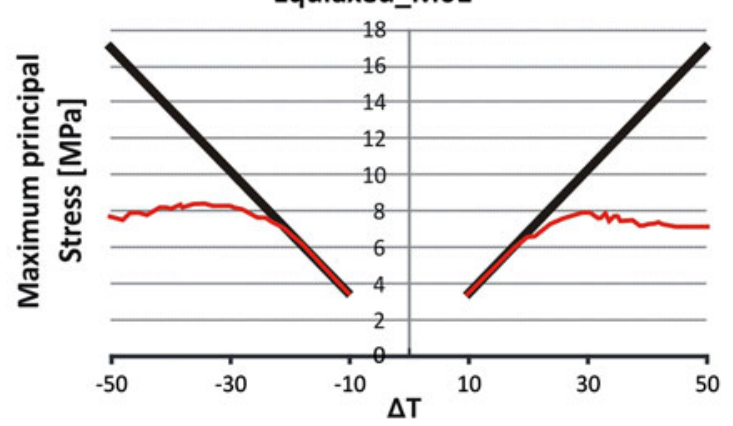

Mixed_M01

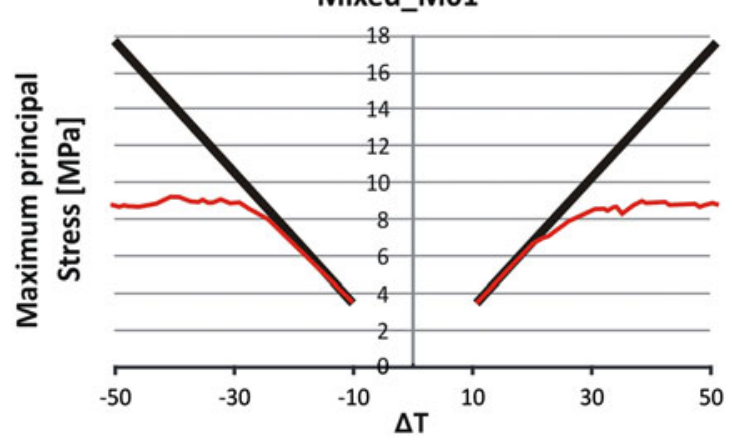

Elongated_M01

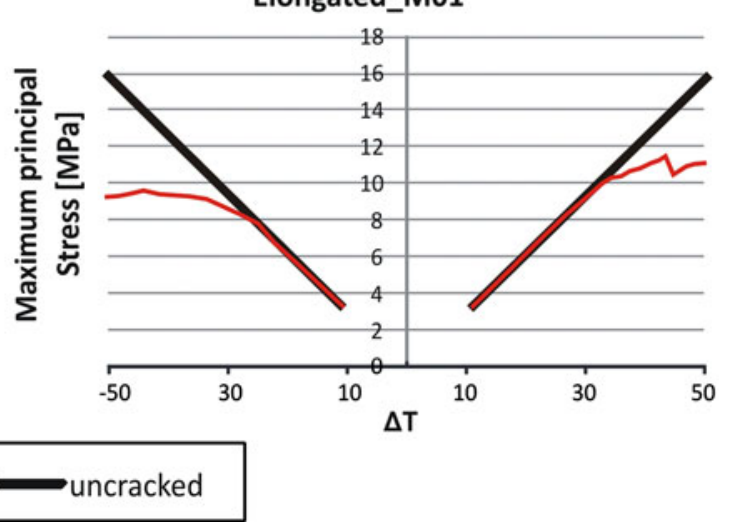

unstressed state. Results are shown for three idealized calcitic microstructures (equiaxed grains, a mixture of equiaxed and elongated grains, and elongated grains) with a nominal grain size of $1 \mathrm{~mm}$ and random texture, denoted as $\mathrm{MO1}$

of whole area upon heating and $4.0 \pm 0.2 \%$ upon cooling (See Fig. 9). The influence of SPO on the degree of microcracking is quite apparent upon heating: there is a sevenfold increase in microcracking when changing from the elongated grain-type to the mixed grain-type microstructure. Upon cooling, the amount of microcracking is greater, but does not increase as significantly with decreasing SPO (only about $20 \%$ for each grain-type change).

The amount of stored elastic strain energy of the uncracked state, as measured by the strain energy density, decreased approximately twofold with increasing LPO. 

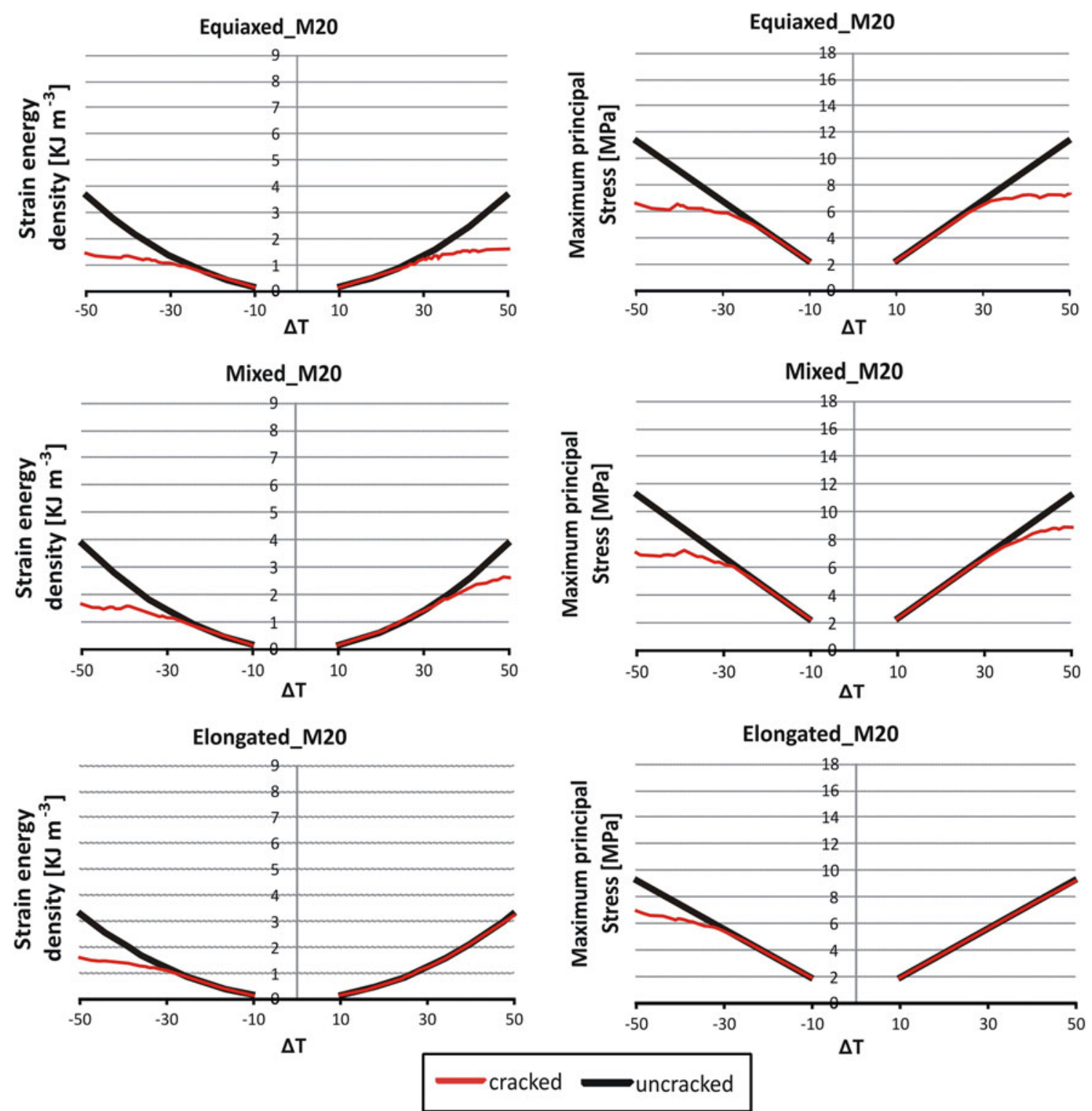

Fig. 7 Representative responses (a single replication of a textured ODF) of the elastic strain energy density and the maximum principal stress for microcracked (red) and unmicrocracked (black) idealized marble microstructures versus the temperature change from the unstressed state. Results are shown for three idealized calcitic

microstructures (equiaxed grains, mixture of equiaxed and elongated grains, and elongated grains) with a nominal grain size of $1 \mathrm{~mm}$ and crystallographic texture that is 20 times random texture (denoted as M20)

However, the amount of stored strain energy of the cracked state decreased only slightly with increasing LPO (Figs. 6, 7). Accordingly, the decrement in elastic strain energy (Fig. 8) and the percentage of microcracked area (Fig. 9) both decrease approximately by $60 \%$ with increasing LPO. Figure 11 provides visualization of the onset and degree of microcracking and of the influence of SPO and LPO.

In the present simulations initiation of microcracks was generally observed to occur at grain triple junctions and along single grain-boundary facets or partial facets.

Subsequent microcracking was mixed mode with a combination of intergranular and transgranular fracture.

Spatial distribution of microcracks

To investigate the relation between maximum principal stress and microcrack initiation and propagation, highstress regions in an uncracked material were compared to the microcracks in the cracked material. Microstructural response maps show the spatial dependence of microcracking and maximum principal stress for an equiaxed 

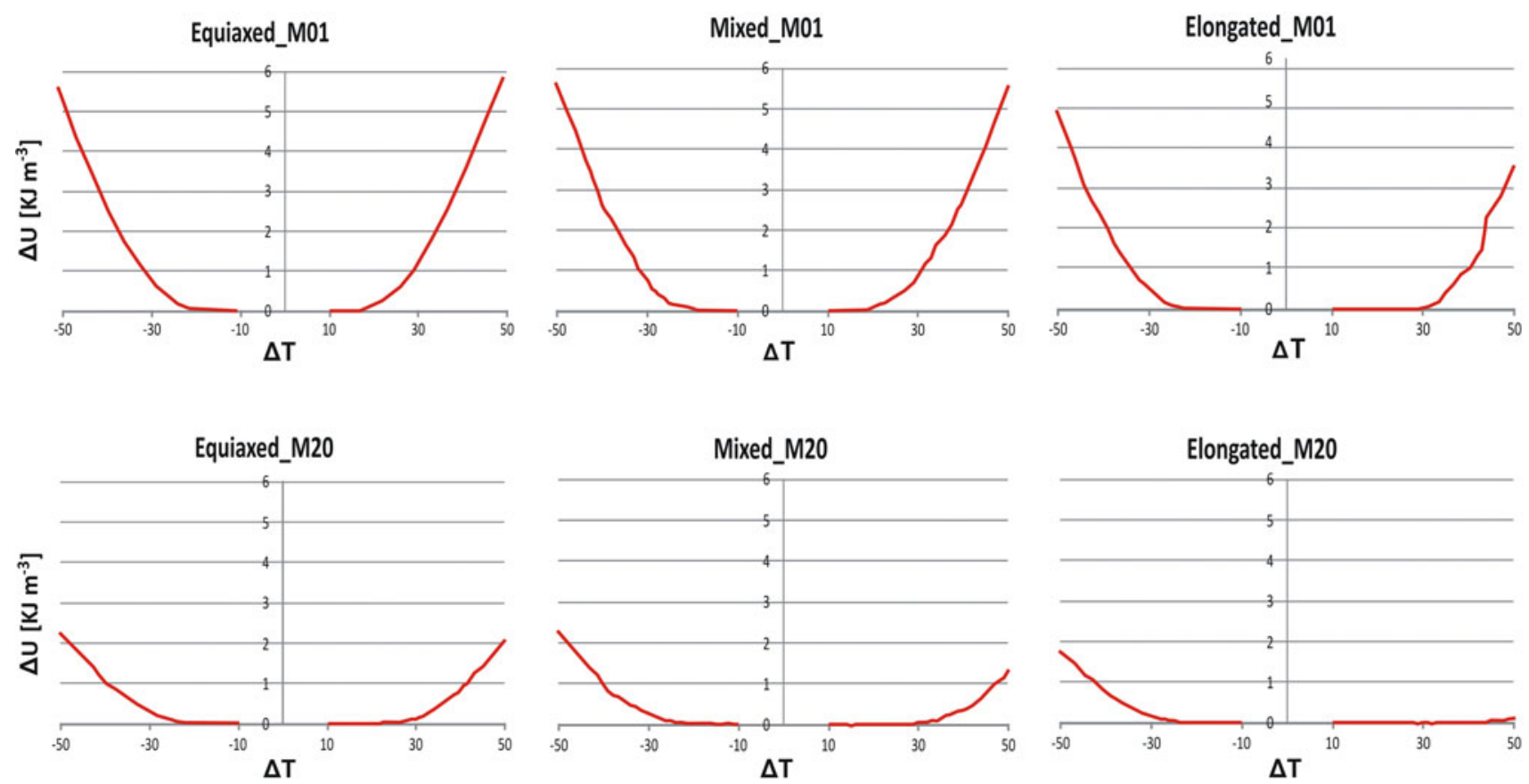

Fig. 8 The decrement in the elastic strain energy density between the unmicrocracked and the microcracked states of idealized calcitic

are shown for random crystallographic texture (denoted M01) and a texture that is 20 times random (denoted as M20) marble microstructures with a nominal grain size of $1 \mathrm{~mm}$. Results

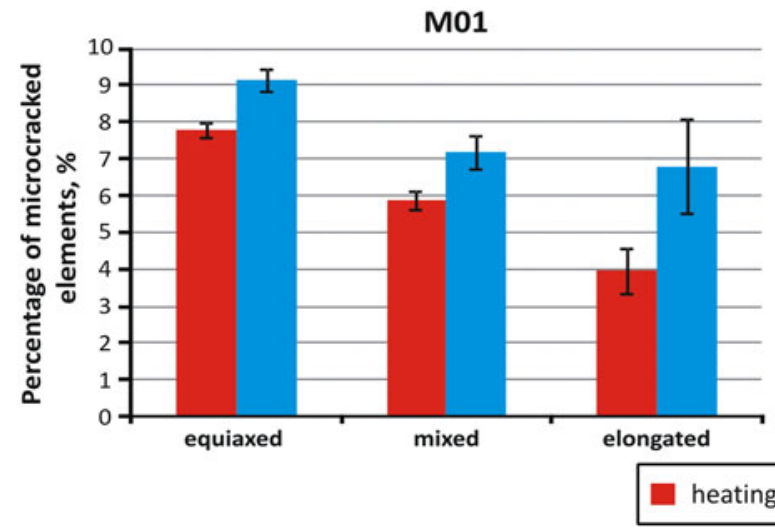

Fig. 9 Averaged percentage of microcracked elements from three replications of the ODF for the three idealized calcitic marble microstructures with a nominal grain size of $1 \mathrm{~mm}$ and random texture (denoted as M01) and texture that is 20 times random (denoted as $\mathrm{M20}$ ). Results are for a temperature change of $+50{ }^{\circ} \mathrm{C}$ (denoted as heating) and $-50{ }^{\circ} \mathrm{C}$ (denoted as cooling). The error bars represent one standard deviation

uncracked state correspond to microcracks in the cracked material. Most of these regions in cracked material have high maximum principal stress as well but the values are smaller than those in the uncracked state. For the uncracked state in a mixed grain microstructure with $M=20$ texture there are fewer regions with high maximum principal stress than in the equiaxed-grain microstructure with random texture, i.e., the propensity for microcracking is less. 
Fig. 10 Simulations of microcracking in an elongatedgrain calcite marble with random texture and a nominal grain size of $1 \mathrm{~mm}$ : a upon heating by a temperature differential $+50^{\circ} \mathrm{C} ; \mathbf{b}$ upon cooling by a temperature differential $-50{ }^{\circ} \mathrm{C}$

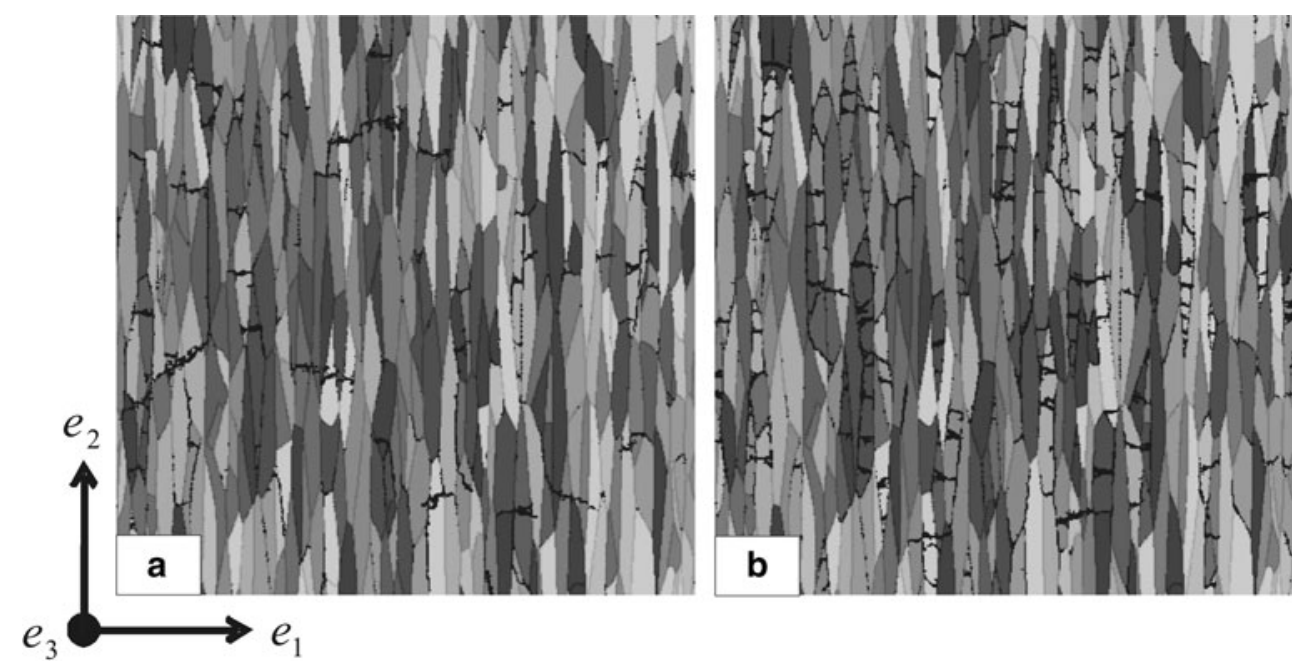

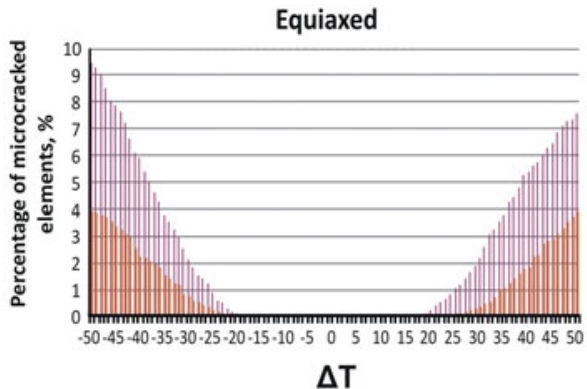

Fig. 11 Representative responses (a single replication of each ODF) of the percentage of microcracked elements for the three idealized calcitic marble microstructures with a nominal grain size of $1 \mathrm{~mm}$

Effect of grain size and marble composition

Extensive microcracking is expected to occur in coarse grain microstructures composed of grains that have a high thermal expansion anisotropy (Cleveland and Bradt 1978). Indeed, given a temperature change, one expects the amount of microcracking to diminish with grain size until a critical grain size is reached, below which microcracking does not occur in finer grain materials. For a temperature change of $\Delta T=50{ }^{\circ} \mathrm{C}$ the critical grain size for calcite is approximately $45 \mu \mathrm{m}$ and that for dolomite is approximately $80 \mu \mathrm{m}$. Thus, in all the grain sizes considered here microcracking is expected to occur for temperature changes of $\pm 50{ }^{\circ} \mathrm{C}$. However, decreasing amounts of microcracking are expected as the grain size decreases from $2 \mathrm{~mm}$ to $1 \mathrm{~mm}$ to $200 \mu \mathrm{m}$.

Accordingly, simulations were performed for calcitic marbles with nominal grain sizes of $200 \mu \mathrm{m}$ and $1 \mathrm{~mm}$, and for dolomitic marbles with nominal grain sizes of 1 and $2 \mathrm{~mm}$. The percentages of microcracked area for the different grain sizes and marble compositions are presented in Table 2. For the $1 \mathrm{~mm}$ grain-size calcitic marble the results upon heating and cooling. Random texture is denoted as $M 01 ; 20$ times random texture is denoted as M20

are averaged over three replications of the ODF to give a mean and standard deviation. For all others fabric configurations the results are only for one replication of the ODF, but one expects similar variability as that for the $1 \mathrm{~mm}$ grain-size calcite.

As expected, the percentage of microcracked area for a total temperature change of $\Delta T=50{ }^{\circ} \mathrm{C}$ is significantly reduced for the $200 \mu \mathrm{m}$ nominal grain-size calcite material in comparison to the $1 \mathrm{~mm}$ grain-size material. In the equiaxed-grain material with random crystallographic texture the microcrack percentage is only $0.5 \%$ of whole area upon heating compared to $7.8 \%$ for the $1 \mathrm{~mm}$ grainsize material. Upon a negative temperature change (cooling) the microcrack percentage is dimensioned even more from 9.1 to $0.4 \%$. While the amount of microcracking for a highly textured material $(M=20)$ is less than that for a material with random texture $(M=1)$, and is not as asymmetric in heating versus cooling, the reduction in the amount of microcracking with grain size is more pronounced: approximately one fortieth when reducing the grain size from $1 \mathrm{~mm}$ to $200 \mu \mathrm{m}$. The mixed grain-shape materials exhibit an even greater decrease in the percentage 

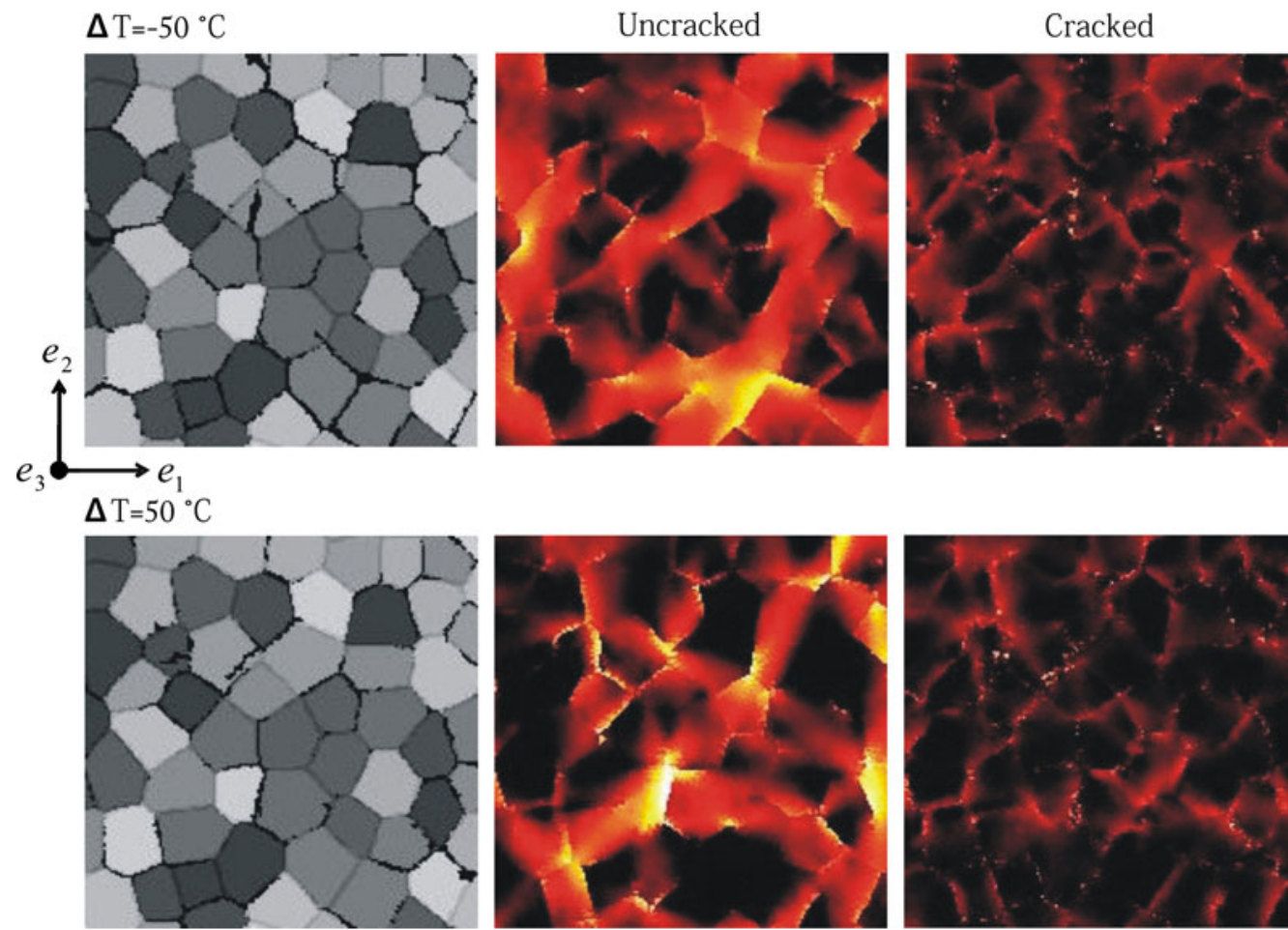

\section{$100 \mathrm{MPa}$}

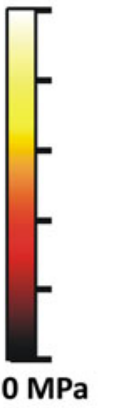

Fig. 12 A cropped selection $(170 \times 170$ pixels $)$ from a microstructural response map showing the spatial dependence of the maximum principal stress for an uncracked and cracked equiaxed-grain calcitic

marble microstructure with a nominal grain size of $1 \mathrm{~mm}$ and a random $\mathrm{ODF}$ for a temperature changes of $\Delta T=-50{ }^{\circ} \mathrm{C}$ and $\Delta T=+50{ }^{\circ} \mathrm{C}$

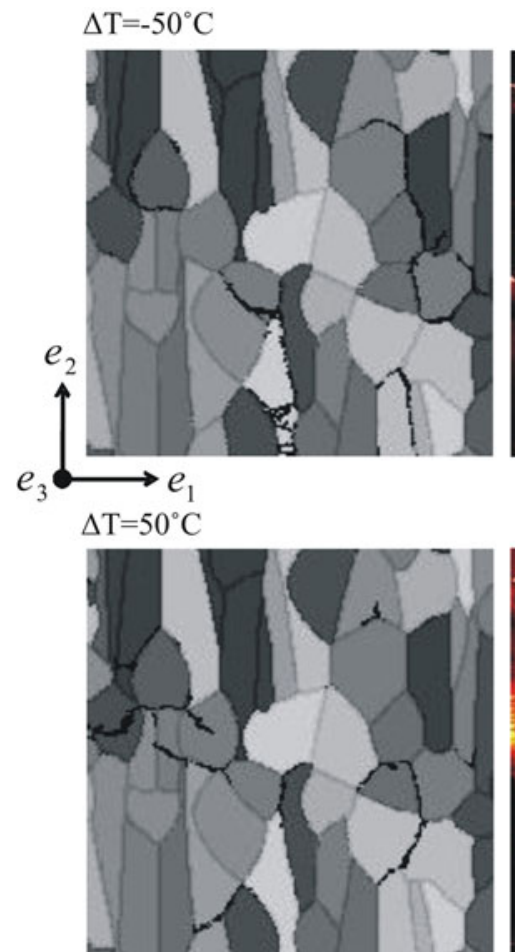

Fig. 13 A cropped selection $(170 \times 170$ pixels $)$ from a microstructural response map showing the spatial dependence of the maximum principal stress for an uncracked and cracked mixed-grain calcitic
Uncracked
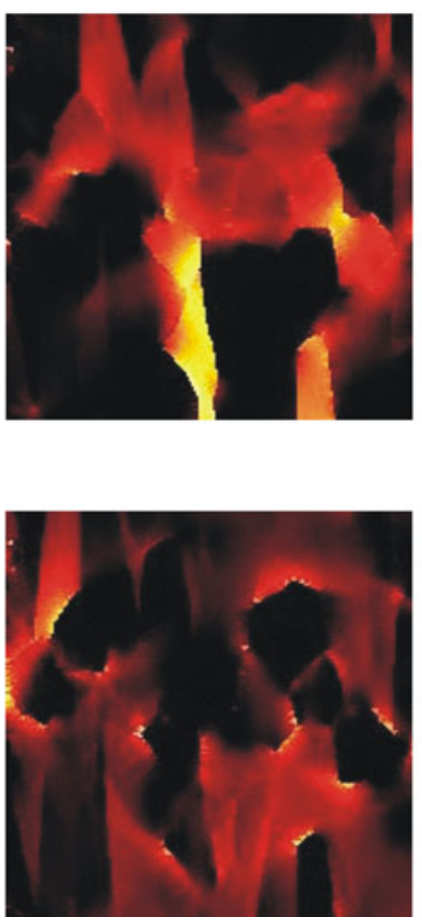

\section{Cracked}
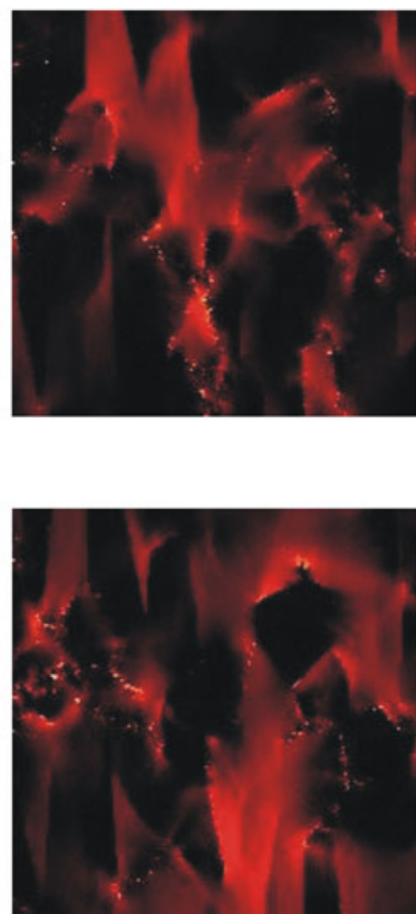

$100 \mathrm{MPa}$

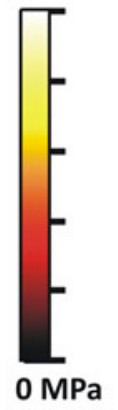

marble microstructure with a nominal grain size of $1 \mathrm{~mm}$ and a highly textured $\operatorname{ODF}(M=20)$ for a temperature changes of $\Delta T=-50{ }^{\circ} \mathrm{C}$ and $\Delta T=+50{ }^{\circ} \mathrm{C}$ 
Table 2 Percentage of microcracked area for three microstructures: equiaxed grains, a mixture of equiaxed and elongated grains, and elongated grains of calcite and dolomite marbles with random texture (denoted as M01) and with strong texture (denoted as M20) after heating and cooling in $1{ }^{\circ} \mathrm{C}$ increments for a total temperature differential of $50{ }^{\circ} \mathrm{C}$

\begin{tabular}{|c|c|c|c|c|c|c|}
\hline & \multicolumn{2}{|c|}{ Equiaxed grains } & \multicolumn{2}{|c|}{ Mixed grains } & \multicolumn{2}{|c|}{ Elongated grains } \\
\hline & M01 (\%) & M20 (\%) & M01 (\%) & M20 (\%) & M01 (\%) & M20 (\%) \\
\hline \multicolumn{7}{|c|}{$200 \mu \mathrm{m}$ grain-size calcite } \\
\hline Heating & 0.5 & 0.1 & 0.3 & 0.004 & 0.007 & 0.00 \\
\hline Cooling & 0.4 & 0.1 & 0.2 & 0.07 & 0.03 & 0.01 \\
\hline \multicolumn{7}{|c|}{$1 \mathrm{~mm}$ grain-size calcite } \\
\hline Heating & $7.8 \pm 0.2$ & $3.8 \pm 0.1$ & $5.9 \pm 0.3$ & $2.2 \pm 0.4$ & $4.0 \pm 0.6$ & $0.3 \pm 0.1$ \\
\hline Cooling & $9.1 \pm 0.3$ & $4.0 \pm 0.2$ & $7.2 \pm 0.5$ & $3.4 \pm 0.3$ & $6.8 \pm 1.3$ & $2.8 \pm 0.4$ \\
\hline \multicolumn{7}{|c|}{$1 \mathrm{~mm}$ grain-size dolomite } \\
\hline Heating & 4.9 & 1.6 & 2.8 & 0.6 & 1.4 & 0.04 \\
\hline Cooling & 5.1 & 2.2 & 3.5 & 1.4 & 2.5 & 1.3 \\
\hline \multicolumn{7}{|c|}{$2 \mathrm{~mm}$ grain-size dolomite } \\
\hline Heating & 8.4 & 2.6 & 6.4 & 2.8 & 5.0 & 0.4 \\
\hline Cooling & 10.8 & 4.1 & 8.4 & 3.8 & 7.7 & 3.1 \\
\hline
\end{tabular}

Fig. 14 Simulations of microcracking in dolomite marble with a nominal grain size of $1 \mathrm{~mm}$ upon heating by a temperature differential $+50{ }^{\circ} \mathrm{C}$ : a equiaxed microstructure with random texture and grain-boundary toughness of $0.40 \gamma_{\text {xtal }}$; b equiaxed microstructure with random texture with grainboundary toughness of $0.20 \gamma_{\mathrm{xtal}}$. The red ellipses identify representative area of comparison
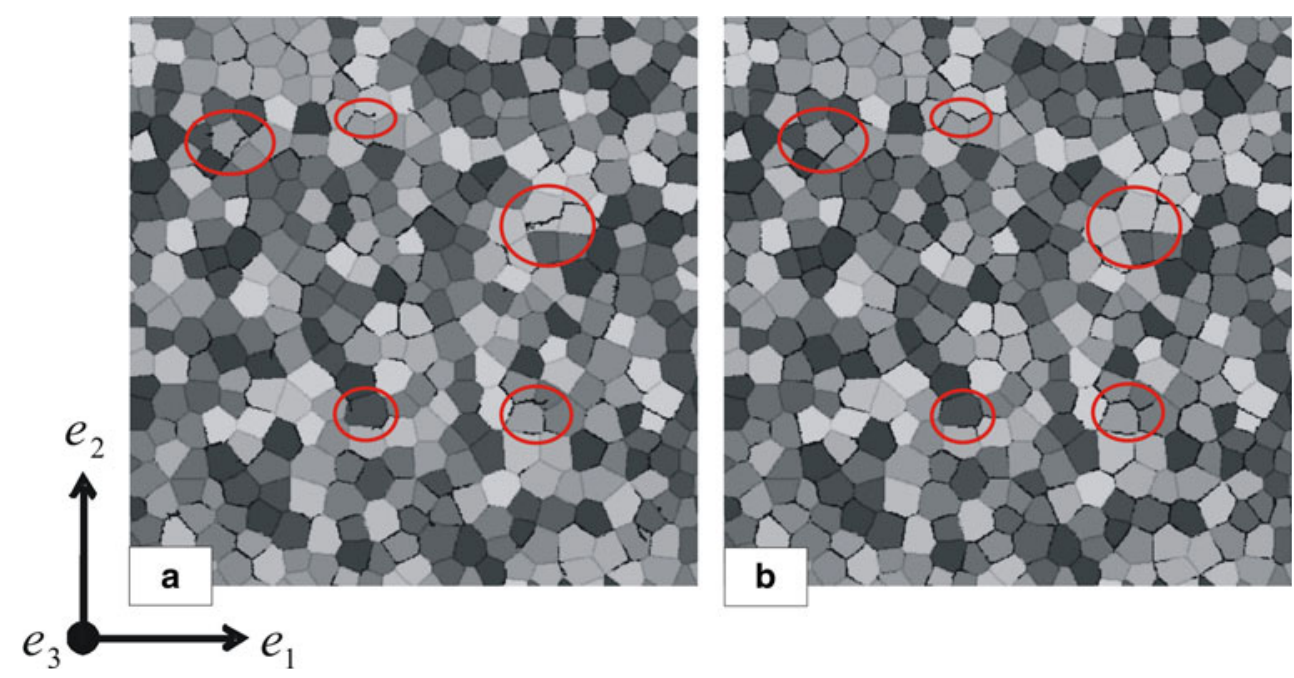

of microcrack area with grain-size reduction (see Table 2). Moreover, the amount of reduction is strongly dependent on the LPO. The $200 \mu \mathrm{m}$ grain size, elongated grain-shape microstructure showed the most significant reduction in microcracking compared to the $1 \mathrm{~mm}$ grain-size material. Almost no microcracking was observed for the $50{ }^{\circ} \mathrm{C}$ temperature change. Furthermore, the reduction in the amount of microcracking for these fabric conditions was strongly dependent on the LPO. For the $200 \mu \mathrm{m}$ elongatedgrain microstructure the percentage of microcracked area was $0.007 \%$ upon heating and $0.03 \%$ upon cooling when the texture is random; and basically $0 \%$ upon heating and $0.1 \%$ upon cooling when there is high LPO texture.

The percentage of microcracked area is also reduced for the $1 \mathrm{~mm}$ nominal grain-size dolomite material compared to the $2 \mathrm{~mm}$ grain-size material (see Table 2). Furthermore, the
$1 \mathrm{~mm}$ grain-size dolomite marble was observed to have less propensity for microcracking than the $1 \mathrm{~mm}$ grain-size calcite marble, i.e., microcracking begins at higher temperature differential and the percentage of cracked area is less (see Table 2). For instance, upon heating an equiaxed microstructure with random texture $(M=1)$ the onset temperature for thermal microcracking occurs at $14{ }^{\circ} \mathrm{C}$ for calcite marble, while the dolomite marble does not begin to crack until $19{ }^{\circ} \mathrm{C}$. While dolomite is stiffer than calcite, calcite has a greater thermal expansion anisotropy resulting in a higher microstructural maximum principal stresses. The percentage of microcracked area in dolomitic marbles with a nominal grain size of $2 \mathrm{~mm}$ is comparable with results for calcitic marble with a nominal grain size of $1 \mathrm{~mm}$.

The simulations also reveal a significant influence of the SPO and LPO fabric parameters on the temperature change 
Equiaxed_M01

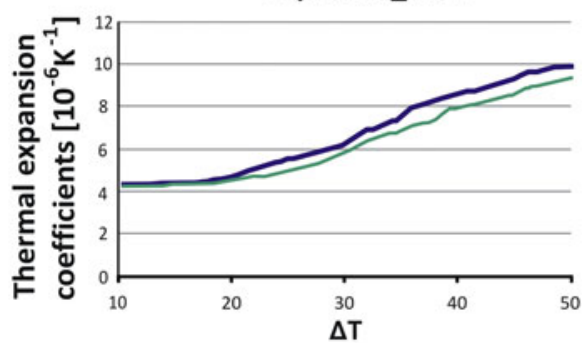

Equiaxed_M01

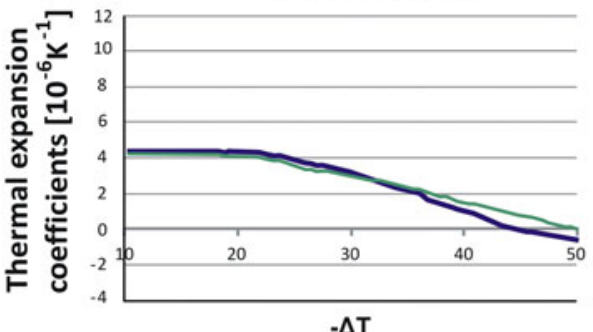

Equiaxed_M20

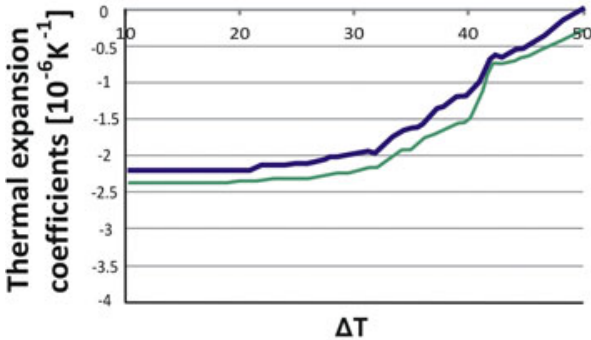

Equiaxed_M20

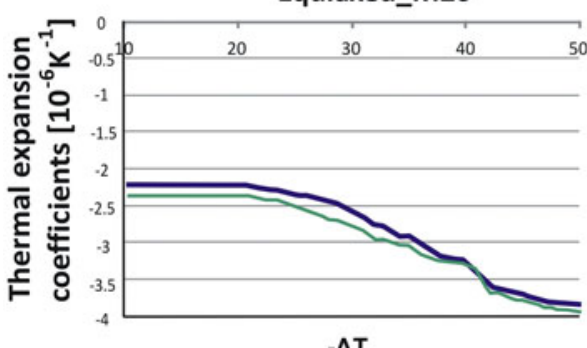

$-\Delta \mathrm{T}$
Mixed_M01

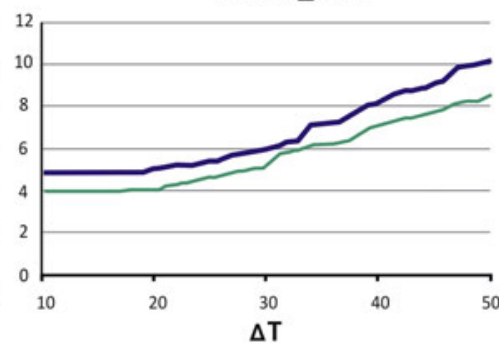

Mixed_M01

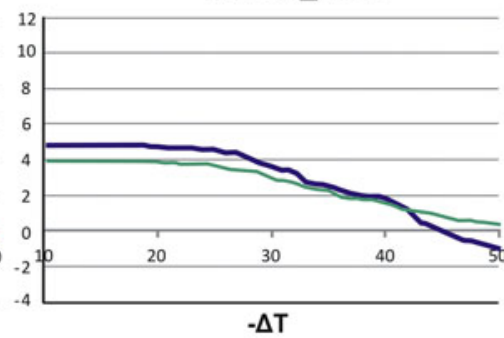

Mixed_M20

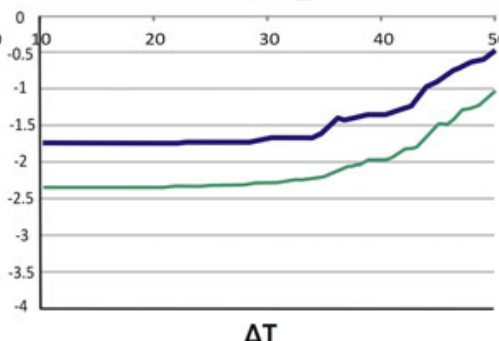

Mixed_M20

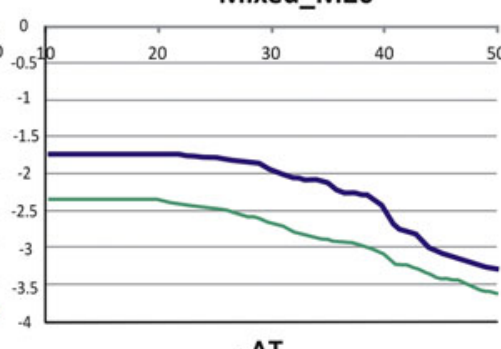

$-\Delta \mathrm{T}$
Elongated_M01

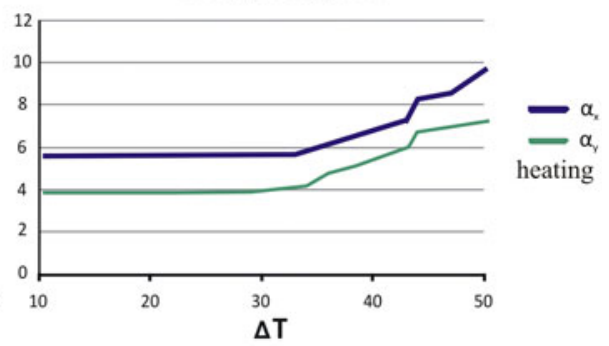

Elongated_M01

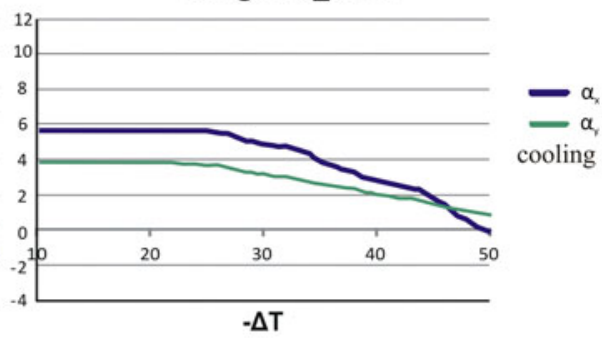

Elongated_M20

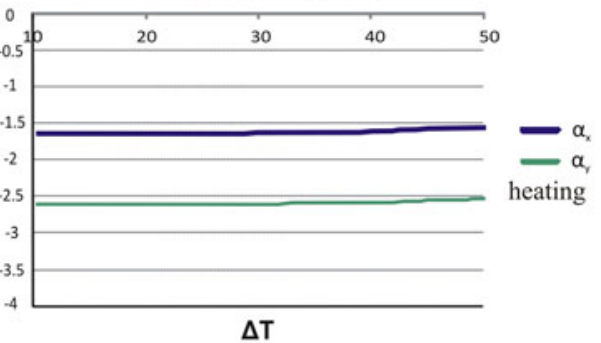

Elongated_M20

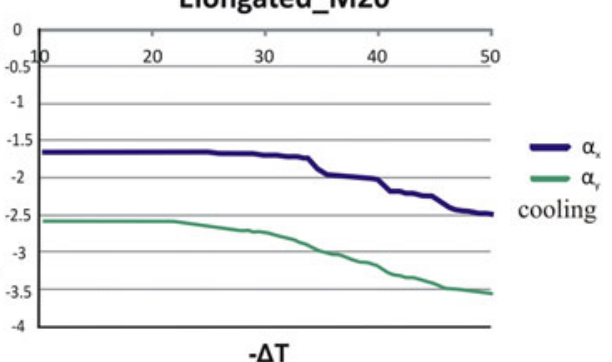

Fig. 15 Polycrystalline thermal expansion coefficients in the $e_{1}$ - and $e_{2}$-directions (denoted as $\alpha_{x}$ and $\alpha_{y}$, respectively) upon heating and cooling by a total temperature differential 50 and $-50{ }^{\circ} \mathrm{C}$ for a calcitic marble with a nominal grain size of $1 \mathrm{~mm}$. Results are shown for one replication

$(\Delta T)$ require for microcrack initiation. The equiaxed-grain calcite microstructure with random texture and a nominal grain size of $200 \mu \mathrm{m}$ begins to crack upon heating at $\Delta T=31^{\circ} \mathrm{C}$ and upon cooling at $\Delta T=-37^{\circ} \mathrm{C}$. In the mixed grain-shape calcite with random texture microcracking commences at $\Delta T=34{ }^{\circ} \mathrm{C}$ upon heating and at $\Delta T=-34{ }^{\circ} \mathrm{C}$ upon cooling. Microcracking in the elongated-grain calcite commences at $\Delta T=45{ }^{\circ} \mathrm{C}$ and at $\Delta T=-40{ }^{\circ} \mathrm{C}$ upon heating and cooling, respectively. For the highly textured calcite $(M=20)$ a larger temperature differential is required for microcracking, namely, $\Delta T=38{ }^{\circ} \mathrm{C}$ and at $\Delta T=-41{ }^{\circ} \mathrm{C}$ in the equiaxed microstructure, $\Delta T=48{ }^{\circ} \mathrm{C}$ and $\Delta T=-34{ }^{\circ} \mathrm{C}$ in mixedshape microstructure, and $\Delta T=50{ }^{\circ} \mathrm{C}$ and $\Delta T=-44{ }^{\circ} \mathrm{C}$ in the elongated-shape microstructure. Indeed, for the elongated-shape fabric microcracking was just initiated at these temperatures, i.e., the first mutated elements in OOF (the procedure in OOF1 for modifying element properties to simulate fracture) occurred at these temperatures.

Effect of grain-boundary toughness

Simulations for dolomite marble with grain size $1 \mathrm{~mm}$ have been performed. The fracture algorithm assumes that the 
Table 3 The coefficients of thermal expansion in units of $10^{-6} \mathrm{~K}^{-1}$ in the $e_{1}$ and $e_{2}$ directions, are denoted as $\alpha_{\mathrm{x}}$ and $\alpha_{\mathrm{y}}$, respectively, upon heating and cooling by a temperature differential 50 and $-50{ }^{\circ} \mathrm{C}$ for microstructure allowing microcracking and for microstructure with no microcracking

\begin{tabular}{|c|c|c|c|}
\hline & Equiaxed & Mixed & Elongated \\
\hline \multicolumn{4}{|c|}{$1 \mathrm{~mm}$ grain size calcite } \\
\hline \multicolumn{4}{|l|}{ M01 } \\
\hline \multirow[t]{2}{*}{ Heating } & $\alpha_{x}=9.84$ & $\alpha_{x}=10.2$ & $\alpha_{x}=9.59$ \\
\hline & $\alpha_{y}=9.27$ & $\alpha_{y}=8.48$ & $\alpha_{y}=7.28$ \\
\hline \multirow[t]{2}{*}{ Cooling } & $\alpha_{x}=-0.64$ & $\alpha_{x}=-1.00$ & $\alpha_{x}=-0.11$ \\
\hline & $\alpha_{y}=0.04$ & $\alpha_{y}=0.38$ & $\alpha_{y}=0.80$ \\
\hline \multirow[t]{2}{*}{ No cracked } & $\alpha_{x}=4.38$ & $\alpha_{x}=4.81$ & $\alpha_{x}=5.63$ \\
\hline & $\alpha_{y}=4.26$ & $\alpha_{y}=3.96$ & $\alpha_{y}=3.85$ \\
\hline \multicolumn{4}{|l|}{ M20 } \\
\hline \multirow[t]{2}{*}{ Heating } & $\alpha_{x}=-0.005$ & $\alpha_{x}=-0.488$ & $\alpha_{x}=-1.580$ \\
\hline & $\alpha_{y}=-0.301$ & $\alpha_{y}=-1.043$ & $\alpha_{y}=-2.529$ \\
\hline \multirow[t]{2}{*}{ Cooling } & $\alpha_{x}=-3.838$ & $\alpha_{x}=-3.290$ & $\alpha_{x}=-2.512$ \\
\hline & $\alpha_{y}=-3.940$ & $\alpha_{y}=-3.622$ & $\alpha_{y}=-3.553$ \\
\hline \multirow[t]{2}{*}{ No cracked } & $\alpha_{x}=-2.221$ & $\alpha_{x}=-1.734$ & $\alpha_{x}=-1.648$ \\
\hline & $\alpha_{y}=-2.370$ & $\alpha_{y}=-2.350$ & $\alpha_{y}=-2.597$ \\
\hline \multicolumn{4}{|c|}{$1 \mathrm{~mm}$ grain size dolomite } \\
\hline \multicolumn{4}{|l|}{ M01 } \\
\hline \multirow[t]{2}{*}{ Heating } & $\alpha_{x}=14.9$ & $\alpha_{x}=14.5$ & $\alpha_{x}=14.1$ \\
\hline & $\alpha_{y}=14.4$ & $\alpha_{y}=10.9$ & $\alpha_{y}=12.7$ \\
\hline \multirow[t]{2}{*}{ Cooling } & $\alpha_{x}=10.5$ & $\alpha_{x}=11.1$ & $\alpha_{x}=12.1$ \\
\hline & $\alpha_{y}=10.9$ & $\alpha_{y}=10.8$ & $\alpha_{y}=11.2$ \\
\hline \multirow[t]{2}{*}{ No cracked } & $\alpha_{x}=12.4$ & $\alpha_{x}=12.7$ & $\alpha_{x}=13.3$ \\
\hline & $\alpha_{y}=12.3$ & $\alpha_{y}=12.1$ & $\alpha_{y}=12$ \\
\hline \multicolumn{4}{|l|}{ M20 } \\
\hline \multirow[t]{2}{*}{ Heating } & $\alpha_{x}=8.9$ & $\alpha_{x}=8.8$ & $\alpha_{x}=8.76$ \\
\hline & $\alpha_{y}=8.63$ & $\alpha_{y}=8.2$ & $\alpha_{y}=7.99$ \\
\hline \multirow[t]{2}{*}{ Cooling } & $\alpha_{x}=7.66$ & $\alpha_{x}=8$ & $\alpha_{x}=8.54$ \\
\hline & $\alpha_{y}=7.55$ & $\alpha_{y}=7.8$ & $\alpha_{y}=7.67$ \\
\hline \multirow[t]{2}{*}{ No cracked } & $\alpha_{x}=8.3$ & $\alpha_{x}=8.6$ & $\alpha_{x}=8.75$ \\
\hline & $\alpha_{y}=8.18$ & $\alpha_{y}=8.2$ & $\alpha_{y}=7.99$ \\
\hline
\end{tabular}

Results are presented for calcite and dolomite marble with a nominal grain size of $1 \mathrm{~mm}$

critical fracture energy of the grain boundary is different from that of the grain interior. Simulations with two grain boundaries toughness are presented, to study the transition from the intergranular to the transgranular mode of crack growth.

More microcracking was observed when the grainboundary toughness $\left(\gamma_{\mathrm{ig}}\right)$ was $20 \%$ of the grain fracture surface energy $\left(\gamma_{x t a l}\right)$ than when it was $40 \%$ of $\gamma_{x t a l}$. Additionally, the microstructure with $\gamma_{\text {ig }}=0.2 \gamma_{\text {xtal }}$ commences to crack at a smaller temperature differential. Spatial maps of the extent of microcracking for a total temperature change of $+50{ }^{\circ} \mathrm{C}$ are shown in Fig. 14. When the grain-boundary toughness is as weak as $20 \%$ of that of the grains, transgranular cracking is essentially reduced completely. Microcracks initiate on single grain-boundary facets or on partial grain-boundary facets, and then propagate along the grain boundaries.

\section{Coefficients of thermal expansion}

The thermal expansion coefficients were computed for a given total temperature change, i.e., for $\Delta T=50^{\circ} \mathrm{C}$ and $\Delta T=-50^{\circ} \mathrm{C}$, and a given microstructure configuration, i.e., for a calcitic and a dolomitic marble with a nominal grain size of $1 \mathrm{~mm}$ and a grain-boundary toughness $0.40 \gamma_{\mathrm{xtal}}$. The thermal expansion coefficient in the $e_{1}$-direction, denoted as $\alpha_{x}$, is computed from the relative displacement change of the right and left sides of the microstructure. The thermal expansion coefficient in the $e_{2}$-direction direction, denoted as $\alpha_{y}$, is computed from the relative displacement change of the top and bottom of the microstructure. Figure 15 illustrates the influence of LPO and SPO on $\alpha_{x}$ and $\alpha_{y}$. Numerical results are presented in Table 3 for the calcitic and dolomitic marbles upon heating and cooling for a total temperature differential of $50{ }^{\circ} \mathrm{C}$. Results are also shown for the case when no microcracking occurs. For these simulations fracture, or microcracking, was inhibited by turning off the cracking algorithm in OOF.

In microstructures with no microcracking the coefficients of thermal expansion (the natural polycrystalline values) are constant during heating and cooling, and the same for both conditions. When microcracking is allowed the coefficients of thermal expansion in the cracked microstructure are greater than the natural polycrystalline values during heating and less than the natural polycrystalline values during cooling (see Fig. 15 and Table 3). This result is indicative of the extra expansion of the microstructure upon microcracking. Microcracks expand the microstructure. So, on heating this additional extension adds to the thermal expansion of the microstructure, thereby giving a larger result. On cooling, this additional expansion due to the microcracks subtracts from the thermal contraction of microstructure, thereby giving a diminished result. With increasing SPO (i.e., equiaxed grains to mixed grain shapes to elongated grains) and increasing LPO (i.e., random crystallographic texture, $M=1$, to highly textured, $M=20$ ), microcracking becomes more spatially anisotropic. When this happens, the difference between $\alpha_{x}$ and $\alpha_{y}$, i.e., $\left(\alpha_{x}-\alpha_{y}\right)$, increases (see Fig. 15). Numerical results in Table 3 for both calcitic and dolomitic materials show a strong dependence on the degree of LPO, and almost no dependence on SPO. 


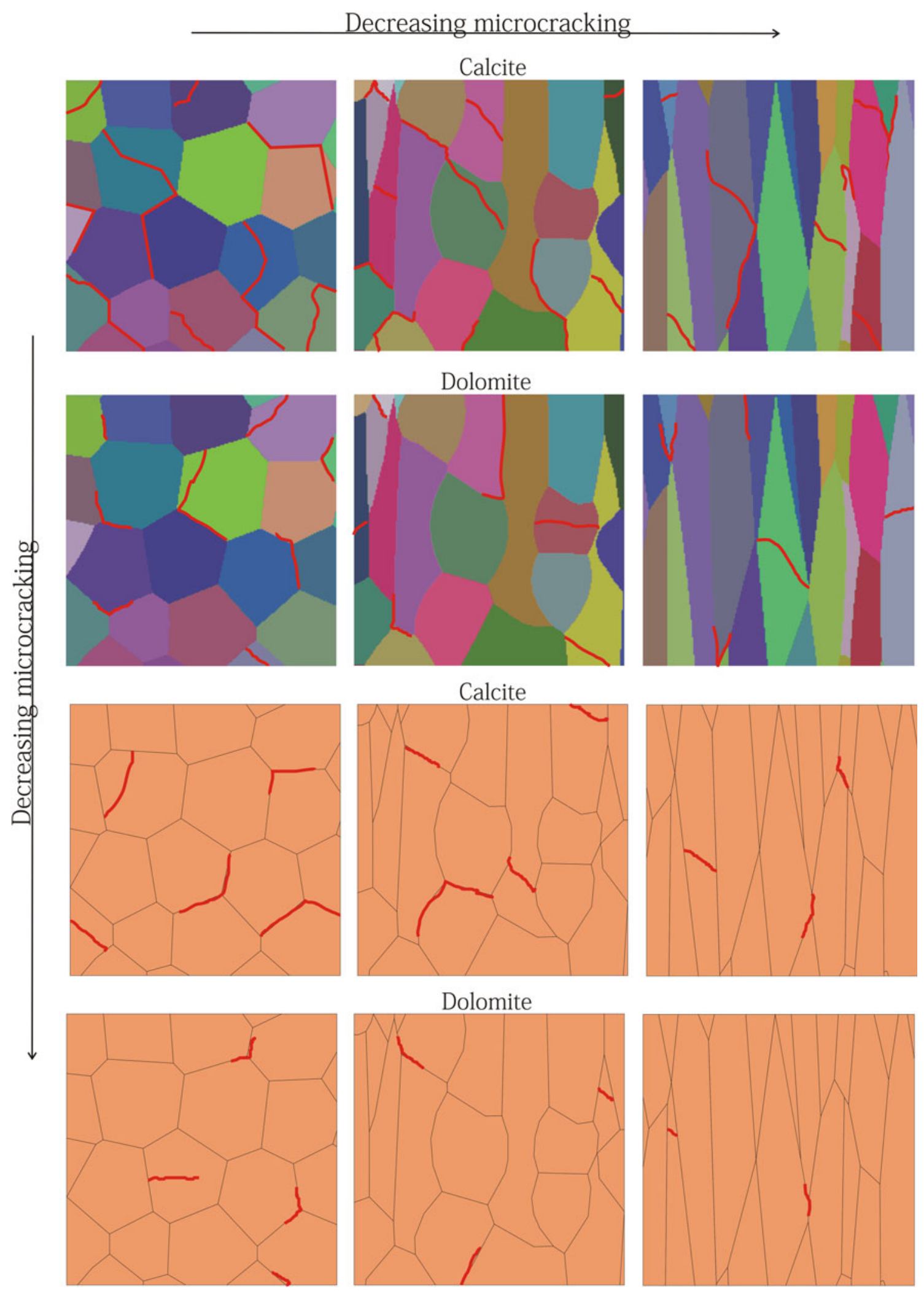

Fig. 16 Idealized illustration of results for calcitic and dolomitic marbles with a grain size of $1 \mathrm{~mm}$ for a temperature change of $\Delta T=-50{ }^{\circ} \mathrm{C}$. Results are shown for three cropped selections of extremes of microstructures (equiaxed grains, a mixture of equiaxed and elongated grains, and elongated grains) with random texture (different colors correspond to different random orientations) and strong texture [similar colors correspond to similar crystalline orientations (i.e., a textured ODF)]. With increasing the degree of texture and shape preferred orientation microcracking (red curves) is decreasing 


\section{Summary and conclusions}

The thermoelastic response of marble and concomitant degradation by microcracking depend on many fabric parameters. The present study revealed certain combination of shape preferred orientation (SPO), lattice preferred orientation (LPO), grain size, grain-boundary toughness, and marble composition that have significant influence on the thermomechanical and degradation behavior of marble.

The elastic strain energy density and the maximum principal stress that result from the thermal expansion anisotropy of the marble crystalline grains and their spatial distribution in the microstructure are excellent indicators of microcracking. Regions in the microstructure with high values of these two microstructural properties in the uncracked state are expected to indicate regions with a propensity for microcracking (Shushakova et al. 2011). It was observed that regions with high maximum principal stress in the uncracked state correspond to microcracks in the cracked material. The onset and degree of microcracking strongly depend on the fabric parameters. With decreasing grain size and increasing LPO and SPO microcracking is less prominent and occurs at a larger temperature differential. Microcracking upon heating is predominantly less than that upon cooling (see Fig. 9). For the case of the mixed-grain and the elongated-grain microstructures with strong crystallographic texture, this asymmetry is significant. The percentage of microcracked area upon heating is one-tenth of that upon cooling.

Marble composition plays an important role in the degree of microcrack degradation. Microcracking in a dolomitic marble commences at higher temperature differential and exhibits less of a tendency to microcrack than for a calcitic marble with the same microstructure and texture. Thus, finite-element simulations indicate that dolomitic marbles are more resistant against thermal degradation. While dolomite is stiffer than calcite, calcite has a greater thermal expansion anisotropy, resulting in higher maximum principal stresses. In agreement, Zeisig et al. (2002) showed experimentally that dolomitic marbles do not have residual strains after thermal treatment. To illustrate the influence of fabric parameters such as marble composition, SPO and LPO on microcracking Fig. 16 is created.

Another fabric parameter that affects microcracking is the grain-boundary toughness $\left(\gamma_{\mathrm{ig}}\right)$. In the simulations the grain-boundary toughness was chosen to be 40 and $20 \%$ of the grain fracture surface energy $\left(\gamma_{x t a l}\right)$ to elucidate the fracture behavior of both transgranular and intergranular crack-growth modes and to bracket the value of the grainboundary fracture toughness that delineates the transition from transgranular fracture to intergranular fracture. For the case of $\gamma_{\text {ig }}=0.4 \gamma_{\text {xtal }}$ microcracking initiated as a grain-boundary microcrack either along a single grainboundary facet or partially along such a facet. Subsequent microcrack extension occurred predominantly along grain boundaries, i.e., intergranular fracture, but occasional excursions through some grains were observed, i.e., intragranular cracks. When the grain-boundary toughness decreased to $20 \%$ of $\gamma_{x t a l}$, the amount of intragranular cracks was greatly reduced, or vanished all together (e.g., see Fig. 14).

Finally, microstructure-based finite-element modeling provides excellent insight and elucidation of influences of rock fabric and crystal texture on the thermoelastic behavior and microcracking response of marbles.

Acknowledgments The authors gratefully acknowledge David M. Saylor for generating the artificial microstructures used in this study with the Microstructure Builder program, which he was developing in collaboration with Carnegie Mellon University and Alcoa Technical Center. Thomas Weiss is gratefully acknowledged for providing the ESEM figures and B.Middendorf as well as B.Grelk for Fig. 1 and Fig. 2b. Financial support for E.R. Fuller, Jr. at Universität Göttingen was provided by the Deutsche Forschungsgemeinschaft grant: SI 438/39-1, and is gratefully acknowledged. Victoria Shushakova gratefully acknowledges a long-term DAAD fellowship grant.

Open Access This article is distributed under the terms of the Creative Commons Attribution License which permits any use, distribution, and reproduction in any medium, provided the original author(s) and the source are credited.

\section{References}

Bass JD (1995) Elasticity of minerals, glasses, and melts. In: Ahrens TJ (ed) Handbook of physical constants. American Geophysical Union, Washington, DC, pp 45-63

Battaglia S, Franzini M, Mango F (1993) High sensitivity apparatus for measuring linear thermal expansion: preliminary results on the response of marbles. II Nuovo Cimento 16:453-461

Becher PF, Freiman SW (1978) Crack propagation in alkaline-earth fluorides. J Appl Phys 49(7):3779-3783

Blendell JE, Vaudin MD, Fuller ER (2004) Determination of texture from individual grain orientation measurements. J Am Ceram Soc 82(11):3217-3220

Carter WC, Langer SA, Fuller ER (1998) The OOF manual: version 1.0. National Institute of Standards and Technology (NIST), NISTIR No. 6256

Chawla N, Patel BV, Koopman M, Chawla KK, Saha R, Patterson BR, Fuller ER, Langer SA (2003) Microstructure-based simulation of thermomechanical behavior of composite materials by object-oriented finite element analysis. Mater Character 49: 395-407

Cleveland JJ, Bradt RC (1978) Grain size/microcracking relations for pseudobrookite oxides. J Am Ceram Soc 61(11-12):478-481

Dollase WA (1986) Correction of intensities for preferred orientation in powder diffractometry: application of the march model. J Appl Crystallogr 19:267-272

Galal Yousef S, Rödel J, Fuller ER, Zimmermann A, El-Dasher BS (2005) Microcrack evolution in alumina ceramics: experiment and simulation. J Am Ceram Soc 88(10):2809-2816 
Grelk B, Goltermann P, Schouenborg B, Koch A, Alnæs L (2004) The laboratory testing of potential bowing and expansion of marble. In: Přikryl R (ed) Dimension stone 2004. Taylor and Francis Group, London, pp 253-260

Griffith AA (1921) The phenomena of rupture and flow in solids. Phil Trans Royal Soc Lond A 221:163-198

Ito O, Fuller ER (1993) Computer modelling of anisotropic grain microstructure in two dimensions. Acta Metall Mater 41(1): 191-198

Kessler DW (1919) Physical and chemical tests on the commercial marbles of the United States. Technologic papers Bureau of Standards, No. 123, Government Printing Office, Washington, DC

Kleber W (1959) Einfiihrung in die Kristallographie. VEB Verlag Technik, Berlin

Koch A, Siegesmund S (2004) The combined effect of moisture and temperature on the anomalous behaviour of marbles. Environ Geol 46:350-363

Langer SA, Fuller ER, Carter WC (2001) OOF: an image-based finite element analysis of material microstructures. Comput Sci Eng 3: 15-23. OOF is freely available at http://www.ctcms.nist.gov/oof/

Leiss B, Ullemeyer K (1999) Texture characterisation of carbonate rocks and some implication for the modeling of physical anisotropies, derived from idealized texture types. Z Deut Geol Ges 150:259-274

Luque A, Ruiz-Agudo E, Cultrone G, Sebastián E, Siegesmund S (2011) Direct observation of microcrack development in marble caused by thermal weathering. Environ Earth Sci 62(7): $1375-1386$

Miodownik M, Godfrey AW, Holm EA, Hughes DA (1999) On boundary misorientation distribution functions and how to incorporate them into three-dimensional models of microstructural evolution. Acta Mater 47(9):2661-2668

Reeder R, Markgraf SA (1986) High temperature crystal chemistry of dolomite. Am Mineral 71:795-804

Royer-Carfagni G (1999) On the thermal degradation of marble. Int J Rock Mech Min Sci 36:119-126

Saylor DM, Fridy J, El-Dasher BS, Jung KY, Rollett AD (2004) Statistically representative three-dimensional microstructures based on orthogonal observation sections. Metall Mater Trans A 35A:1969-1979

Saylor DM, Fuller ER, Weiss T (2007) Thermal-elastic response of marble polycrystals: influence of grain orientation configuration. Int J Mat Res 98(12):1256-1263 (formerly Z. Metallkd.)
Shushakova V, Fuller ER, Siegesmund S (2011) Influence of shape fabric and crystal texture on marble degradation phenomena: simulations. Environ Earth Sci 63:1587-1601

Siegesmund S, Ullemeyer K, Weiss T, Tschegg EK (2000) Physical weathering of marbles caused by anisotropic thermal expansion. Int J Earth Sci 89:170-182

Siegesmund S, Koch A, Ruedrich J (2007) Ursachen mangelnder Formbeständigkeit von Fassadenplatten: Fallstudie Universitätsbibliothek der Universität Göttingen. In: Siegesmund S, Ehling A (eds) Rohstoff Naturstein Teil 1. Z dt Ges Geowiss 158: 630-648

Siegesmund S, Ruedrich J, Koch A (2008) Marble bowing: comparative studies of different public building facades. In: Siegesmund S, Snethlage R, Ruedrich J (eds) Monumental future: climate change, air pollution, stone decay and conservation. Environmental geology 56:473-494

Wanner T, Fuller ER, Saylor DM (2010) Homology metrics for microstructure response fields in polycrystals. Acta Mater 58: $102-110$

Weiss T, Siegesmund S, Fuller ER (2002) Thermal stresses and microcracking in calcite and dolomite marbles via finite element modelling. In: Siegesmund S, Weiss T, Vollbrecht A (eds) Natural stone, weathering phenomena, conservation strategies and case studies. Geological Society Special Publication No. 205, The Geological Society of London, London, pp 89-102

Weiss T, Siegesmund S, Fuller ER (2003) Thermal degradation of marble: indications from finite-element modelling. Build Environ 38(9-10):1251-1260

Weiss T, Saylor DM, Fuller ER, Siegesmund S (2004) Prediction of the degradation behaviour of calcareous rocks via finite-element modelling. In: 10th International congress on deterioration and conservation of stone, Stockholm, pp 163-170

White GS, Freiman SW, Fuller ER, Baker TL (1988) Effects of crystal bonding on brittle fracture. J Mater Res 3(3):491-497

Winkler EM (1994) Stone in architecture: properties, durability, 3rd edn. Springer, Berlin

Zeisig A, Siegesmund S, Weiss T (2002) Thermal expansion and its control on the durability of marbles. In: Siegesmund S, Weiss T, Vollbrecht A (eds) Natural stone, weathering phenomena, conservation strategies and case studies. Geological Society Special Publication No. 205, The Geological Society of London, London, pp 65-80

Zimmermann A, Carter WC, Fuller ER (2001) Damage evolution during microcracking of brittle solids. Acta Mater 49:127-137 